\title{
Equilibrium analysis, banking, contagion and financial fragility
}

\author{
Dimitrios P Tsomocos
}

Working Paper no. 175

e-mail: dimitrios.tsomocos@sbs.ox.ac.uk

Said Business School, University of Oxford, Park End Street, Oxford, OX1 1HP.

Bank of England, FMG and University of Oxford. The views expressed are those of the author and do not necessarily reflect those of either the Bank of England or the FMG of the LSE or the University of Oxford.

I am grateful to W Buiter, E Catarineu-Rabell, S Hayes, F Heinz, C Goodhart, S Millard, E Nier, D Pain, R Repullo, H-S Shin, M Shubik, seminar participants at the Bank of England, 56th ESEM, Economics University of Athens, LSE, Indian Statistical Institute, University of Athens, University of Frankfurt, V CSAET, XI Workshop on General Equilibrium, Yale University and especially Pradeep Dubey, Glenn Hoggarth and Geoffrey Wood for helpful comments and remarks. However, all remaining errors are mine. I would also like to thank Stelios Leonidou and Milan Kutmutia for excellent research assistance.

Copies of working papers may be obtained from Publications Group, Bank of England, Threadneedle Street, London, EC2R 8AH; telephone 0207601 4030, fax 02076013298 , e-mail mapublications@bankofengland.co.uk

Working papers are also available at www.bankofengland.co.uk/wp/index.html

The Bank of England's working paper series is externally refereed. 


\section{Contents}

Abstract

$\begin{array}{ll}\text { Summary } & 7\end{array}$

1. Introduction $\quad 9$

2. The market structure and the transmission mechanism 12

3. The model 16

3.1 The economy 16

3.2 Government, central bank and the regulator 18

3.3 The time structure of markets 19

3.4 Secondary asset markets 21

3.5 Money and credit markets 22

3.6 Default 24

3.7 Capital requirements 26

3.8 The commodity markets 27

3.9 Stocks, flows and liquidity constraints 27

3.10 Commercial banks 28

3.11 Interbank credit market 29

4. The budget set 30

$\begin{array}{lll}4.1 & N B P S & 30\end{array}$

4.2 Commercial banks 31

5. Equilibrium 32

6. Orderly function of markets: existence 35

7. Financial fragility, contagion and systemic risk 38

7.1 Financial fragility: concepts and definitions 38

7.2 An example: changes in capital requirements 40

7.3 Liquidity trap 40

7.4 On bank runs 42

7.5 Constrained inefficiency 43

8. Concluding remarks 44

$\begin{array}{ll}\text { References } & 45\end{array}$

$\begin{array}{ll}\text { Appendix I } & 49\end{array}$

Appendix II $\quad 52$

$\begin{array}{ll}\text { Appendix III } & 57\end{array}$ 


\begin{abstract}
This paper contains a general equilibrium model of an economy with incomplete markets (GEI) with money and default. The model is a simplified version of the real world consisting of a non-bank private sector, banks, a central bank, a government and a regulator. The model is used to analyse actions by policy-makers and to identify policy relevant empirical work. Key analytical results are: a financially fragile system need not collapse; efficiency can be improved with policy intervention; and a system with heterogeneous banks is more stable than one with homogeneous ones. Existence of monetary equilibria allows for positive default levels in equilibrium. It also characterises contagion and financial fragility as an equilibrium phenomenon.
\end{abstract}

A definition of financial fragility is proposed. Financial fragility occurs when aggregate profitability of the banking sector declines and defaults in the non-bank and banking private sectors increase. Thus, equilibria with financial fragility require financial vulnerability in the banking sector and liquidity shortages in the non-bank private sector.

The model will be used as a basis to carry out empirical work on the costs of financial instability, to quantify the effectiveness of particular regulatory tools such as capital requirements, and to identify trade-offs between increasing stability through action by authorities and the efficiency of the financial system.

Key words: Financial fragility, contagion, competitive banking, capital requirements, incomplete markets, default.

JEL classification: D52, E4, E5, G1, G2. 


\section{Summary}

An analytical framework that can be used to examine financially fragile regimes and to show how financial crises develop is presented. An attempt is made to produce a rigorous yet tractable model of contagion and financial fragility. It integrates a range of well-known and widely discussed phenomena, such as bank runs, endogenous default and the liquidity trap, in a formal monetary general equilibrium model with missing financial markets.

The standard general equilibrium with incomplete markets model with money and default is extended by incorporating a competitive banking sector. Commercial banks are heterogeneous and are assumed to maximise expected profits subject to bank-specific state-dependent capital requirements. The non-bank private actors maximise utility of consumption subject to liquidity constraints. The model extends over two periods, and uncertainty is resolved in the second. Assets are traded in the first period and pay off in the second.

Trade in an equity market for ownership shares of commercial banks, as well as in the interbank credit market occurs in the first period. Commodity and non-bank private sector credit markets operate in both periods. Cash in advance is needed for all market transactions and both households and banks are allowed to default on their financial obligations. The government determines fiscal policy whereas the central bank sets monetary policy. Finally, a regulatory agency legislates the bankruptcy code and fixes capital requirements and time-varying risk weights.

Existence of monetary equilibria with commercial banks and default (MECBD) allows for positive default levels in equilibrium. Also, financially fragile regimes are compatible with the orderly functioning of markets. Existence is guaranteed provided that there are sufficient gains-from-trade in the economy. When financial markets are inactive, the rates of delivery are honoured by government via an organisation such as Federal Deposit Insurance Corporation.

A definition of financial fragility is proposed. An economic regime is financially fragile when substantial default of a 'number' of households and banks (ie a liquidity 'crisis'), without necessarily becoming bankrupt, occurs and the aggregate profitability of the banking sector decreases significantly (ie a banking 'crisis').

A version of the liquidity trap holds where banks engage in large asset trades, without changing interest rates in the non-bank private sector's credit markets, no matter how expansionary monetary policy is. Commercial banks do not channel the increased liquidity to the consumer credit markets but the asset market, and therefore increased activity is observed in asset transactions. So, commodity prices remain relatively unaffected.

The Diamond-Dybvig result is a special case of MECBD in which banks are homogeneous and financial contagion due to default is maximal. But if, on the other hand, loans are financed entirely by capital, there should be no spill-over effects. There is a trade-off between financial stability and efficiency, since stricter capital requirements generate higher interest rates and thus reduce efficient trade and limit banks' risk-taking behaviour.

It is also shown that under certain restrictions and binding capital requirements, equilibria are constrained inefficient. Therefore, if the government or the regulator intervened in period 0 through transfers, taxation or by modifying the capital requirements of the economy, it could achieve a Pareto improvement on the original equilibrium. Consequently, optimal regulatory policy exists, and it depends on the particular parameters of the economy. 
Finally, the quantity theory of money proposition, in which both prices and quantities adjust in response to policy changes, holds. The term structure of interest rates is specified and accommodates both the expectations and liquidity preference hypotheses. Default influences the shape of the yield curve. Also, monetary, fiscal and regulatory policy changes are non-neutral only when interest rates are positive and the policy variables change disproportionately.

Within this framework, which displays several crucial characteristics of the financial system in its current form, it has been possible to show how financial fragility manifests itself in the continuum, and may not precipitate a financial crisis if the appropriate measures are adopted. Active regulatory policy may be used to improve welfare and alter the distributional effects of financial fragility. 


\section{Introduction}

This paper seeks to develop an analytical framework that can be used to examine financially fragile regimes and to show how financial crises develop. An attempt is made to produce a rigorous yet tractable model of contagion and financial fragility. It integrates a range of well known and widely discussed phenomena such as bank runs, endogenous default and the liquidity trap in a formal general equilibrium framework.

Recent financial crises such as the Texas banking during the 1980s, in Scandinavia and the United Kingdom in the early 1990s, in Mexico in 1995, East Asia in 1997, Russia in 1998, the near-collapse of LTCM, and Japan throughout the 1990s have renewed interest in studying financial instability. Its origins, propagation mechanisms, macroeconomic consequences and ultimately its containment are some of the issues that have recently attracted attention. A clear understanding of financially unstable regimes is a prerequisite for crisis management and prevention as well as prudential regulation. International organisations have proposed and legislated measures to help ensure financial stability in the global markets and to reduce its systemic externality. For example, the BIS proposed a New Accord (Basel Committee on Banking Supervision (2001)) for capital requirements in February 2001.

A difficulty in analysing financial instability lies in the fact that most of the crises manifest themselves in a seemingly unique manner. A plethora of models, primarily game-theoretic in nature, have been introduced to address financial instability. After the seminal papers of Bryant (1982) and Diamond and Dybvig (1983), several authors (eg Allen and Gale (1998, $2000))^{(1)}$ have attempted to rationalise bank-runs and panics based on some type of co-ordination failure. Most of them depend on asymmetric information and some type of moral hazard. More recently, Morris and Shin (2000) suggested an argument stemming from co-ordination failure and switching strategies that offers an explanation for some of the recent currency crises.

Some additional minimum structural characteristics should be present in any model attempting to capture fundamental aspects of financial instability. First, it should be multiperiod, with aggregate uncertainty and agent heterogeneity. Different actions and policy recommendations are necessary for crisis resolution depending on the structure of economic uncertainty and the impact on various economic sectors. Second, money and liquidity constraints should be explicit, since financial crises evolve from the nominal sector and subsequently spread to the real economy. Third, since the performance of banks is critical for the study of financial fragility and contagion a banking sector well integrated in the model is indispensable to any modelling attempt. Finally, the regulatory framework should be clearly defined for policy and sensitivity analysis of various regulatory regimes.

This paper follows a slightly novel approach in modelling contagion and financial fragility. Almost always a common feature of most crises is increased default and lower profitability in the banking sector. Empirical studies (Crockett (1997), Gonzalez-Hermosillo (1999) and International Monetary Fund (1998)) show that the amount of non-performing loans increases markedly before and during a crisis, and bank profitability falls. A definition of financial fragility that depends on an increase of default by the non-bank private and banking sectors and reduced bank profitability is suggested. It allows for analysis of financial stability issues as a continuum of possible contingencies, whereas standard definitions usually consider only polar

\footnotetext{
${ }^{(1)}$ For an excellent survey of these models see the textbook by Freixas and Rochet (1998), where most of them are presented. Also, see Allen and Gale $(1998,2000)$ where the recent contributions of Allen and Gale are presented.
} 
situations, tantamount to financial crises. Analysing financial instability in a continuum implies that crisis prevention policies may be applied before an actual crisis materialises. Such policies cannot be easily analysed in a Diamond-Dybvig framework.

The main characteristic of the model is its incomplete asset markets structure. In the real world, there are insufficient financial instruments to insure against all future contingencies. The 'empirical' proof of market incompleteness is the extent of financial innovation. If markets were complete there would be no further need for financial innovation and security design since all risks could be insured. There are many reasons why markets are incomplete. For example, transaction costs may be sufficiently high to preclude the opening of a market, or asymmetric information may be such that a particular asset market may not be established. For example, there are no financial asset markets to insure against aggregate macroeconomic risks. Incomplete markets are also important from a policy perspective. Equilibria of incomplete asset market models are constrained inefficient. Put differently, the authorities can play a crucial role in improving welfare. Thus there are multiple instruments the government, central bank and/or the regulator might use to improve upon an inefficient equilibrium, and mitigate or prevent the detrimental consequences of financial fragility.

In this paper, the standard GEI model with money and default (as in Dubey and Geanakoplos (1993) and Dubey, Geanakoplos and Shubik (2000)) is extended by incorporating a competitive banking sector. Commercial banks are heterogeneous and are assumed to maximise expected profits. They are owned by their shareholders who have bought shares (as in Shubik and Tsomocos (1992)). This modelling approach allows for a variety of financial institutions, not just commercial banks. The key distinction between financial intermediaries and the non-bank private actors is while the former maximise profits the latter maximise utility of consumption. Banks differ among themselves with respect to initial capital endowments, risk preferences and assessments of future scenarios (ie subjective probabilities). The modelling of the banking sector is akin to Tobin (1982): banks borrow from the non-bank private sector (NBPS) and from the central bank via the interbank credit market and extend credit to the NBPS via the consumer credit markets. They also hold a diversified portfolio of securities.

The remaining characteristics of the model are standard. Bank specific capital requirements are state dependent and may depend on macroeconomic variables such as output or default. The model extends over two periods, and uncertainty is resolved in the second. Assets are traded in the first period and pay off in the second. An equity market for ownership shares of commercial banks meets in the first period. The central bank interacts with commercial banks via the interbank market in the first period and loan settlement occurs in the second. There exists one intraperiod consumer credit market per state and one interperiod consumer credit market, in which commercial banks extend credit to households. Thus, commercial banks can be viewed as creators of 'money' (as in Tobin (1963)). Commodity markets meet in each state. Cash-in-advance is needed for all market transactions (as in Clower $(1965,1967)$ and Shubik (1973)). Both households and banks are allowed to default on their financial obligations. They are penalised proportionally to their size of default by subtracting a linear term from their respective objective functions. Banks lose profit and consumers lose utility.

The model has parallels in the overlapping generations literature, in the work of Lucas and his followers, and in the growing literature of dynamic new Keynesian models. ${ }^{(2)}$ All of these literatures maintain all three aspects of the general equilibrium paradigm (ie market clearing,

\footnotetext{
${ }^{(2)}$ For an extensive survey of this class of models, see Bernanke, Gertler and Gilchrist (1999).
} 
agent optimisation and rational expectations). Unlike the approach here, though, they resort to infinite horizon. The infinite horizon introduces several inconvenient features. First, multiple equilibria are possible whereas, these can be avoided, in principle, with finite horizon and a minimum of institutional detail such as liquidity constraints or a banking sector. A further difficulty is that an infinite horizon makes the model almost completely intractable from a computational point of view. ${ }^{(3)}$ Indeed, in order to make his model tractable, Lucas makes the heroic assumption of the representative agent. Trade is motivated by giving a 'split' personality to the representative agent: it trades with itself at some moments, and pools all its resources at other moments.

Bernanke, Gertler and Gilchrist (1999) avoid the representative agent hypothesis in the strict sense but they introduce risk-neutrality. That is commensurate with passive economic activity in as much as economic agents neither diversify nor hedge. In addition, restricted agent and bank heterogeneity (as in the case of Bernanke, Gertler and Gilchrist (1999), whose model does not have banks) restricts the usefulness of these models since income and welfare redistribution cannot be addressed. Also, endogenous default (an indispensable feature of financial instability) is not present in any of these literatures. Finally, most of their results are driven either by ad hoc institutional structures.

The closest precursor to the present model is the work of Shapley and Shubik (1977), Shubik (1973) and Shubik (1999) who introduced a central bank with exogenously specified stocks of money and cash-in-advance constraints in a strategic market game. Shubik (1973) also emphasised the virtues of explicitly modelling each transaction (see also Grandmont (1983), Grandmont and Laroque (1973), Grandmont and Younes (1972,1973), who introduced a banking sector into general equilibrium with overlapping generations). The commercial banking sector of this model follows closely Shubik and Tsomocos (1992), who used, however, gold-backed money and modelled a mutual bank with fractional reserves. Finally, the modelling of money and default in an incomplete markets framework is akin to the models developed by Dubey and Geanakoplos (1992), and Dubey, Geanakoplos and Shubik (2000). However, Dubey and Geanakoplos $(1992,1993)$ is a one-period model with money and default, Dubey and Geanakoplos (1993) includes incomplete asset markets and money, and Dubey, Geanakoplos and Shubik (2000) has incomplete asset markets, default and no money. None of the previous papers combines all three ingredients, incorporates a competitive commercial banking sector, and focuses on financial fragility. In addition, Dubey and Geanakoplos (1992) introduced the gains-from-trade hypothesis and private monetary endowments that guarantee positive value of money in finite horizon as well as positive interest rates. ${ }^{(4)}$ Default is modelled as in Shubik (1973) and Shubik and Wilson (1977), namely by subtracting a linear term from the objective function of the defaulter proportional to the debt outstanding.

In the next section (Section 2), the market structure of the model and the transmission mechanism of financial fragility are described. In Section 3, the model is formally presented and the roles of the central bank, government, the regulator and commercial banks are analysed. Sections 4-5 formally describe the budget sets of the households, the commercial banks and the monetary equilibrium with commercial banks and default (MECBD). Prices are determined by a process which is equivalent to tatonnement under the competitive condition of this paper. Section 6 establishes the existence of MECBD provided that the necessary gains-from-trade are present in

\footnotetext{
(3) At the same time all of them avoid the backward induction value of money puzzle (ie fiat money having zero value at the last period and thus all the way to the first period fiat money is not used by anybody) by working in an infinite horizon which has no last period from which to start the backward induction.

(4) Alternatively, one needs positive default as in Shubik and Tsomocos (1992), and Shubik and Wilson (1977).
} 
the initial allocation. Put differently, the ratio of the aggregate monetary endowment of households and initial capital of commercial banks relative to the money injected by the central bank in the interbank market determines the interest rate. This rate should not be so high as to deter market transactions. (The ratio of these monetary aggregates is what determines the term structure of interest rates equation that is derived in Appendix III.) Besides supporting a positive value of fiat money in a finite horizon, MECBD manifest two seemingly paradoxical properties. First, agents may choose in equilibrium a positive level of default. Second, financially fragile regimes are compatible with the orderly function of markets. The importance of the last property is that financial vulnerability presents itself to the financial system as an externality with real effects; consequently, there is a role for specific policy instruments to deal with it.

A formal definition of financial fragility is proposed in Section 7 and properties of MECBD which are relevant to financial fragility are examined. In particular, a version of the Keynesian liquidity trap holds in which commodity prices stay bounded whereas asset trades tend to infinity whenever monetary policy is loosened. This situation corresponds to a financially fragile equilibrium. The seminal Diamond and Dybvig (1983) result is shown to depend upon the homogeneity of commercial banks. Theorem 2 shows that MECBD are constrained inefficient provided that there is no default and capital requirements are binding. In Section 8, concluding remarks and some potential extensions are noted.

Proofs are contained in Appendix II.

Appendix III contains the quantity theory of money proposition in which both prices and quantities adjust in response to policy changes. This result differs from Lucas $(1980,1990)$, and Lucas and Stokey (1987) because he postulated a 'sell-all model' in which every agent sells everything he owns in every period, so the number of transactions is fixed by definition. In this model agents transact only if they wish to do so. Moreover, in order to make his model more tractable, he relies on the representative agent hypotheses. The term structure of interest rates is specified. The expectations and the liquidity preference hypothesis are accommodated and default influences the shape of the yield curve. Results for the issues of determinacy, non-neutrality and the relationship among MECBD, GEI and GE are offered. Monetary, fiscal and regulatory policy changes are non-neutral only when interest rates are positive and the policy variables change disproportionally. This property of non-neutrality is ultimately connected with real and nominal determinacy of MECBD. Consequently, policy changes that affect the nominal sector of the economy necessarily generate real effects. ${ }^{(5)}$ The model may be used more widely to address issues of both monetary and financial stability since it contains an integral monetary sector.

\section{The market structure and the transmission mechanism}

The model consists of markets for commodities, tradable financial assets, consumer credit, interbank credit and banks' equity. There exist $L S^{*}$ commodity markets that meet at $t=0$ and $t=1$. The financial side of the economy contains $J$ secondary asset markets and one short-term credit market per state. In addition, there exists one long-term credit market. Shares of commercial banks are traded in the primary equity market. The structure of the markets is summarised in Figure 2.

\footnotetext{
${ }^{(5)}$ Discussion of these results, as well as their proofs, is contained in Tsomocos (2000).
} 
The structure of the model shown in Figure 1 is similar to the market structure of Geanakoplos and Tsomocos (2002). There are commodity markets for each traded commodity and credit markets in which the NBPS acquires its short and long-term financing. As in the incomplete markets literature, assets can be traded today and deliver a promised payoff in the future. If the respective payoff consists of both physical commodities and money the asset is called a real asset; if it consists of only money it is called a financial asset. The most important financial asset is the so-called riskless asset whose promised payoff is 1 across all future states. The asset market captures the functions of the secondary market since it does not include initial public offerings of assets. Finally, market incompleteness ('missing financial markets') is captured by assuming that there are fewer assets than future states of the world. No attempt is made to derive market incompleteness endogenously; this is beyond the scope of this paper.

The banking sector interacts with the central bank via the interbank credit market and supplies credit to the NBPS via the credit markets. Monetary policy is conducted in the interbank market with open market operations and is affected by interbank lending. Commercial banks hold a diversified portfolio of securities through investments in the asset market. Thus, their assets consist of loans and their positions in the asset market. In addition to their initial capital endowment, commercial banks issue equity, which may be acquired by the investors. The model is closed by distributing the profits of the banking sector (if any) back to the shareholders. 
Figure 1

Market structure of the model

\section{GOVERNMENT, CENTRAL BANK, REGULATOR \\ Open market operations}

Fiscal policy

Bankruptcy code $(\lambda)$

Capital adequacy ratio $(k)$

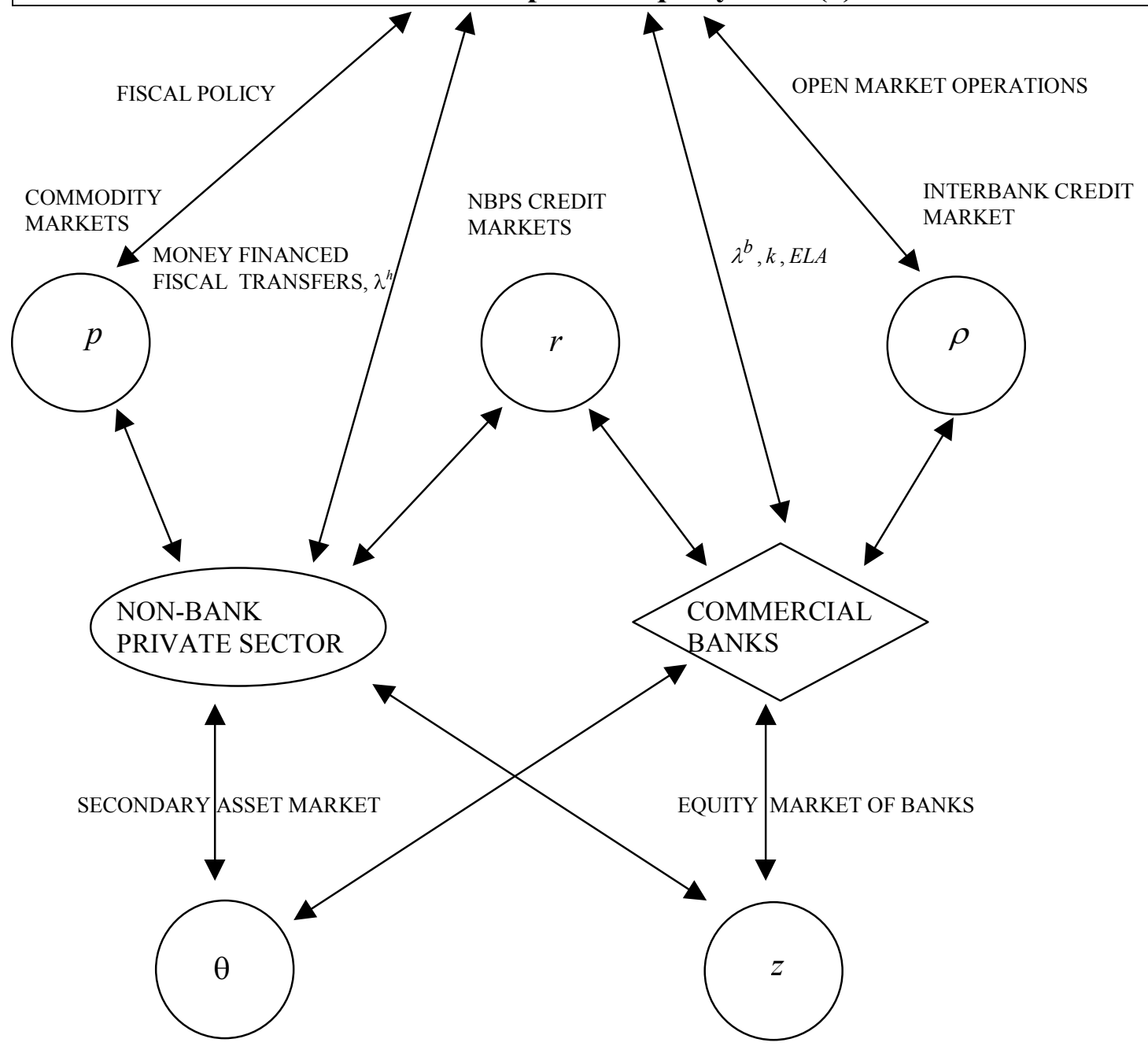

Where,

$p \quad=$ Commodity prices

$r \quad=$ Credit market interest rate

$\rho \quad=$ Interbank interest rate

$\theta \quad=$ Asset prices

$z \quad=$ Equity prices

$\lambda^{h} \quad=$ Bankruptcy penalties imposed on investors

$\lambda^{b} \quad=$ Bankruptcy penalties imposed on banks

$E L A=$ Emergency liquidity assistance 
Financial fragility manifests itself through the presence of endogenously determined default. Figure 2, shows how monetary, fiscal and regulatory policy affect financial fragility.

\section{Figure 2 \\ How policy affects financial fragility}

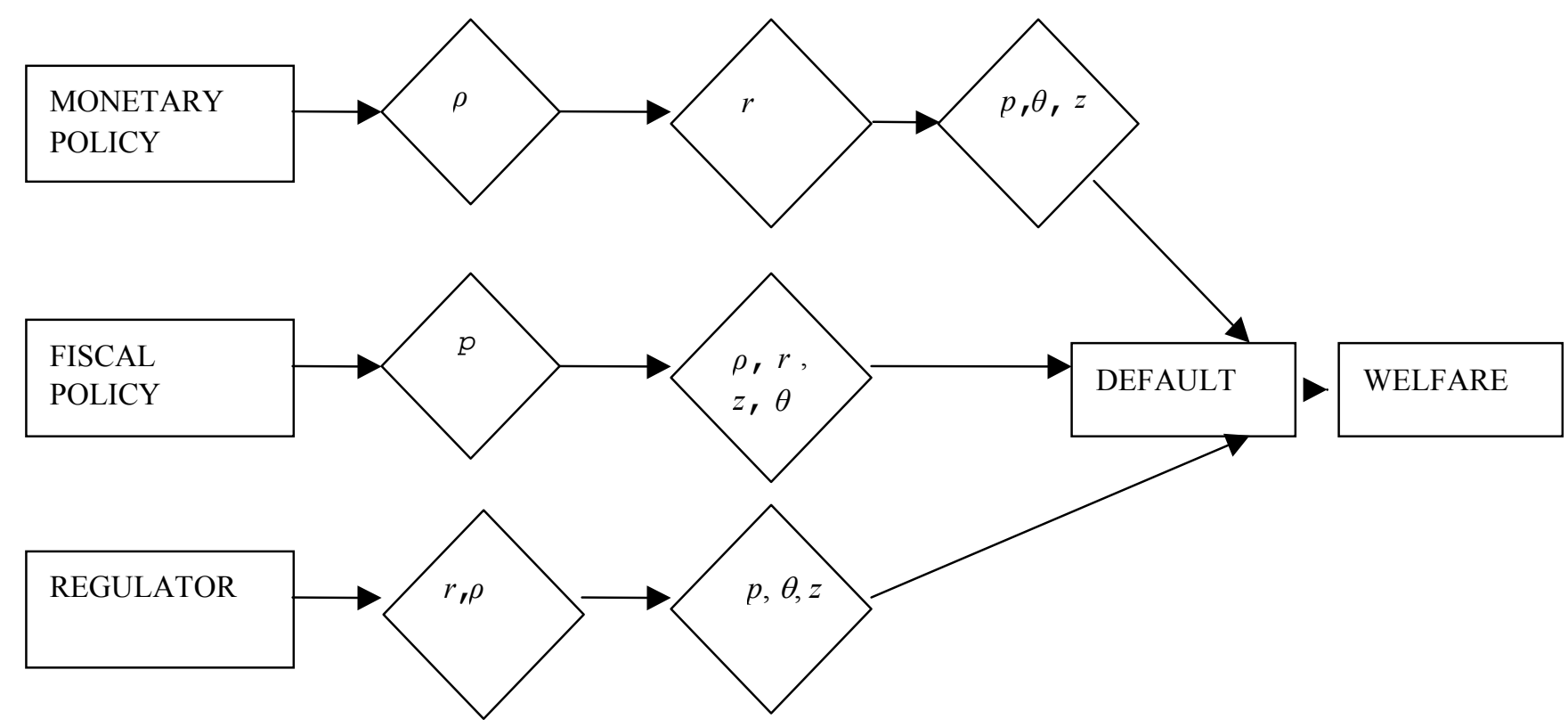

\footnotetext{
${ }^{1}$ Variables are denoted with the same symbols as in Figure 1.

${ }^{2}$ Note that the direct channels only are indicated and I have omitted the channels and the effects that the equilibrating mechanisms of the various markets generate.

${ }^{3}$ As discussed below, default here does not necessarily imply welfare losses since the cost of default may be outweighed by the purchasing power of excess liquidity.
}

Monetary policy determines the interbank interest rate $(\rho)$ which in turn affects, via the actions of commercial banks, the term structure of interest rates in the credit markets $(r)$. In equilibrium, commodity and asset prices are established and default levels are optimising choices of commercial banks and the NBPS. Given specific bankruptcy penalties and regulatory minimum risk-weighted asset ratios, investors and banks rationally weight the marginal benefit versus the cost of defaulting in forming their portfolios. For example, if bankruptcy penalties were infinitely high then default would be prevented altogether but at the expense of welfare improving transactions and investments that might require a less risk-averse attitude. In other words, there exists a trade-off between the severity of the bankruptcy code and investment behaviour in the economy.

Similarly, fiscal policy operates through the commodity markets, which then affect the credit, equity and asset markets. In addition, the government may be engaged in capital injections by directly providing equity capital to individual commercial banks (as was the case, for example, in the Swedish and Japanese banking crises in the early 1990s). Finally, regulatory policy, either through the default penalty $(\lambda)$ or capital adequacy ratio $(\kappa)$, establishes respectively a lower and an upper bound on interest rates. In particular, $\kappa$ sets a ceiling for the maximum bank credit expansion given the central bank's monetary policy. Similarly, the specification of $\lambda$ imposes a 
floor on prices below which the marginal cost of default exceeds the marginal benefit, and therefore determines a lower bound on interest rates.

\section{The model}

\subsection{The economy}

Consider the standard general equilibrium model with incomplete markets in which time extends over two time periods. The first period consists of one state and the second period consists of $S$ possible states. Figure 1 describes the state space of the model. In $t=0$, NPBS, commercial banks and the authorities take their decisions expecting the realisation of any one of the $S$ possible future scenarios to occur. At $t=1$ one of the $S$ states occurs and then again the economic actors take the appropriate decisions. A detailed explanation of the sequence of events is contained in Section 3.3 and Figure 4. NBPS and commercial banks transact, maximising their respective objective functions, whereas the government, central bank and the regulator are modelled as 'strategic dummies' (ie their choices are exogenously fixed and are common knowledge to economic agents). NBPS trades in commodities, assets, consumer loans and shares of commercial banks. Commercial banks lend to the credit markets and take deposits, and they borrow and lend in the interbank credit market. Finally, they invest in marketed assets and auction their shares of ownership in the equity market. The consolidated government/central bank operates in the interbank credit market via OMOs and conducts fiscal policy intervening in the commodity markets and through money-financed fiscal transfers. The regulator fixes the bankruptcy code for households and commercial banks exogenously and sets the capital-adequacy requirements for the commercial banks.

\section{Figure 3}

State space

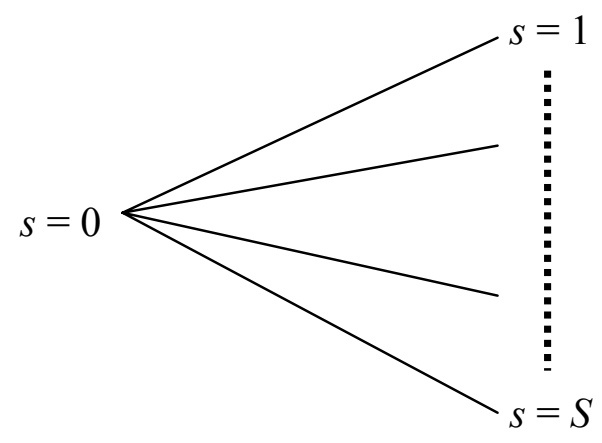

$$
t=0 \quad t=1
$$

Formally, the notation that will be used henceforth is as follows:

$t \in T=\{0,1\}=$ time periods,

$s \in S=\{1, \ldots, S\}=$ set of states at $t=1$,

$S^{*}=\{0\} \cup S=$ set of all states,

$h \in H=\{1, \ldots, H\}=$ set of economic agents (NBPS),

$b \in B=\{1, \ldots, B\}=$ set of commercial banks,

$l \in L=\{1, \ldots, L\}=$ set of commodities,

$R_{+}^{L} \times R_{+}^{S L}=$ commodity space indexed by $\{0, \ldots S\} \times\{1, \ldots L\}$, 
$e^{h} \in R_{+}^{L} \times R_{+}^{S L}=$ endowments of commodities of NBPS, ${ }^{(6)}$

$e^{b} \in R_{+}^{S^{*}}=$ capital endowments of commercial banks.

NBPS trade in financial assets to bet or to hedge. The speculative motive is incorporated in their utility functions by assigning different subjective probability assessments over all the future states of the world and the hedging motive by assuming that they maximise the expected utility of consumption rather than expected consumption per se.

$u^{h}: R_{+}^{L} \times R_{+}^{S L} \rightarrow R=$ utility function of agent $h \in H$,

$\chi_{s l}^{h} \equiv$ consumption of commodity $l$ in state $s$ by $h \in H$.

The standard assumptions hold:

(A1) $\forall s \in S^{*}$ and $l \in L, \sum_{h \in H} e_{s l}^{h}>0$,

(ie every commodity is present in the economy.)

(A2) $\forall s \in S^{*}$ and $h(b) \in H(B), e_{s l}^{h}>0\left(e_{s}^{b}>0\right)$ for some $l \in L\left(s \in S^{*}\right)$,

(ie no household (commercial bank) has the null endowment of commodities (capital) in any state of the world.)

(A3) Let $A$ be the maximum amount of any commodity $s l$ that exists and let 1 denote the unit vector in $R^{S L x L}$. Then $\exists Q>0 \ni u^{h}(0, \ldots Q, \ldots 0)>u^{h}$ (A1) for $Q$ in an arbitrary component

(ie strict monotonicity in every component - the higher consumption the better). ${ }^{(7)}$ Also, continuity and concavity are assumed.

The money supply expansion mechanism of the economy highlights the causal importance of introducing multiple banks with an active role in the system. Regulatory intervention in the financial system occurs primarily through the banking industry (eg capital-adequacy ratios etc). It is evident that the liquidity of the monetary economy as well as the equilibrium outcomes are affected by the risk profiles of commercial banks. Risk preferences determine commercial banks' composition of assets. Finally, the heterogeneity of banks is a crucial ingredient of analysing systemic effects of exogenous shocks occurring in a continuum of possible outcomes. The issue of bank heterogeneity is addressed by letting banks have different initial monetary endowments and utility functions of profits. Finally, concavity (ie risk aversion) entails active behaviour since agents do not take as given the actions of everybody else.

$u^{b}: R_{+}^{S^{*}} \rightarrow R=$ utility function of bank $b$

$\pi_{s}^{b}=$ monetary holdings of $b$ at $s \in S^{*}$.

${ }^{(6)}$ In Section 3.5, monetary endowments will be allowed.

(7) The results remain unaltered if, instead of the previous condition, we assume smoothness of $u^{h}$. 
Two straightforward assumptions are imposed.

(A4) $\forall s \in S^{*}$ and $b \in B, e_{s}^{b}>0$,

(ie no bank has the null endowment at any state.)

(A5) Let $A_{m}$ be the maximum amount of money present in the economy and let 1 denote the unit vector in $R^{s^{*}}$. Then $\exists Q>0 \quad \ni \quad u^{b}(0 \ldots, Q, \ldots 0)>u^{b}\left(A_{m} 1\right)$

for $Q$ in an arbitrary component (ie strict monotonicity in every component - the higher profits are the better). ${ }^{(8)}$ Also continuity and concavity are assumed.

\subsection{Government, central bank and the regulator}

There is a public sector, which has the capacity to act on markets through, for example, the central bank. The public sector comprises of the government (fiscal authority) and the central bank; they are of course separate bodies. A regulatory agency legislates the bankruptcy code of the economy and fixes the banking sector's minimum regulatory capital adequacy requirements. Both of these institutions' actions are exogenously specified and the consequences of their choices are analysed.

The public sector (ie including the central bank) buys commodities, implements money financed fiscal transfers and conducts open market operations in the interbank credit market. Government purchases of commodities are part of fiscal policy. ${ }^{(9)}$

Formally, the following vector (using the notation on page 5) gives the government and central bank's actions

$$
\left(M^{G}, \mu^{G}, m^{G}, b^{G}\right) \equiv\left(M^{G} ; \mu^{G},\left(m_{h s}^{G}\right)_{h \in H \cup B, s \in S^{*}} ;\left(b_{s l}^{G}\right)_{s \in S^{*}, l \in L}\right)
$$

where,

$$
\begin{aligned}
& M^{G}=\text { OMOs on behalf of the government/central bank, } \\
& \mu^{G}=\text { bond sales by the government/central bank, } \\
& m^{G}=\text { money financed fiscal transfers to households and emergency liquidity assistance } \\
& \text { to commercial banks, }
\end{aligned}
$$

and $\quad b^{G}=$ fiscal policy.

Note that the government is not required to spend less than it borrows; the existence of equilibrium is compatible with the central bank printing money to finance its expenditures. All

\footnotetext{
(8) The results remain unaltered if, instead of the previous condition, we assume smoothness of $u^{b}$.

(9) One can extend the choice set of government to include taxation. See Geanakoplos and Tsomocos (2002) for details.
} 
the results hold for both cases, (ie with or without money financing) except where otherwise stated. $^{(10)}$

Similarly, the following vector gives the regulator's actions

$(\kappa, \lambda, \omega) \equiv\left(\left(\kappa_{s}^{b}\right)_{b \in B, s \in S} ;\left(\lambda_{s}^{h}\right)_{h \in H \cup B, s \in S} ;\left(\omega_{i j}^{b}\right)_{b \in B, i \in S, j \in \Omega}\right)$ where,

$\kappa^{\prime} \mathrm{s}$ are the time varying capital-adequacy ratios prevailing in the commercial banking sector, $\lambda$ 's are the bankruptcy penalties imposed upon the parties breaking their contractual obligations and $\omega$ 's are the time-varying risk weights of bank assets that apply for the calculation of the capital requirements (time varying risk weights are consistent with the new Basel Accord). The analysis of default and bankruptcy is conducted in Section 3.6 and of the capital requirements in Section 3.7.

\subsection{The time structure of markets}

In each time period the following market transactions occur:

At $t=0$, the commodity, asset, equity, credit (long and short) and interbank markets meet. At the end of the first period consumption and settlement (ie principal, interest rate and bankruptcy penalties payment) of the one-period loans take place.

At $t=1$, the commodity and short-term credit markets meet, and long-term loans and assets are delivered. At the end of the second period consumption and settlement of the interbank, long-term and second period short-term loans defaults take place. Capital requirements need to be met at the end of each period for each state.

It is assumed that commodities are perishable, lasting only one period, and that each market meets once in each period. Aside from putting an upper bound on the velocity of money, the drawback of this simplification is that the order in which the markets meet needs to be carefully chosen. ${ }^{(11)}$ The reason for this is to maintain the cash-in-advance requirement (ie to ensure that agents have the money before they spend it).

Figure 4, makes the time line of the model explicit. It includes the various moments at which the different loans are due. The ordering of the markets is unimportant if the time horizon $T$ is large (and if goods are durable). The specific order shown (with credit markets first) is shown so as to maximise the amount of possible trading activity per period since the focus is on events stemming from the financial sector of the economy.

Note that fiscal policy and bankruptcy settlements occur in both periods and money financed fiscal transfers occur at every $s \in S^{*}$ before any activity has taken place. Lender of last resort support (LOLR) to individual banks is understood as money financed fiscal transfers to

\footnotetext{
${ }^{(10)}$ However, at the end of $t=1$ the government observes its budget constraints. As discussed in Tsomocos (2000), money non-neutrality depends on the positive interest rate and not exclusively on government financing.

(11) These problems are avoided with durable goods. In that case the periods could be regarded as arbitrarily close together and the order of market transactions inside a period would become irrelevant. If market $\alpha$ preceded market $\beta$ inside each period, an agent could always trade on market $\beta$ in period $t$ and then wait a 'nanosecond' to trade in market $\alpha$ in period $t+1$ if that is the order he preferred.
} 


\section{Figure 4}

\section{Time structure of the model}

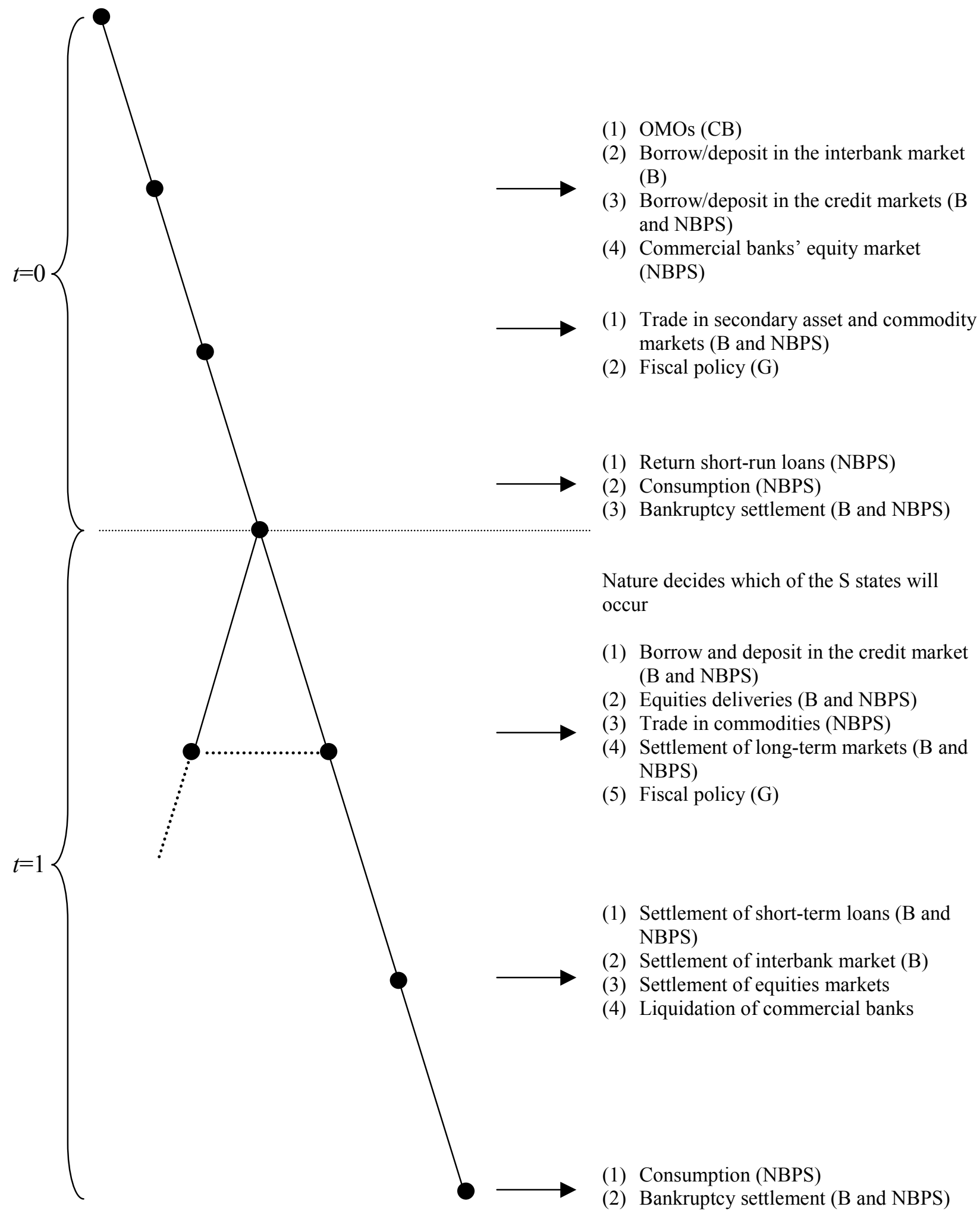

$\mathrm{G} \quad=$ Government/central bank

$\mathrm{CB} \quad=$ Central bank

$\mathrm{B} \quad=$ Commercial banks

NBPS $=$ Non-bank private sector

Without loss of generality, I present a two-period version of the model. The same sequence of transactions apply for any finite horizon (ie $T=(0,1 \ldots T)$ ). 
commercial banks. Also, liquidity injections in the interbank market can be thought of as aggregate LOLR support to the market in response to an exogenous adverse shock. An example is Federal Reserve intervention in the aftermath of the 1998 Asian crisis. This type of intervention is tantamount to Emergency Liquidity Assistance (ELA) to the market as a whole.

\subsection{Secondary asset markets}

The set of assets is $J=\{1, \ldots J\}$. Assets are promises sold by the seller in exchange for a price paid by the buyer today. They are traded at $t=0$ and the contractual obligations are delivered at $t=1$ at a particular state $s \in S$. An asset $j \in J$ is denoted by a vector $A^{j} \in R_{+}^{S(L+1)}$ indicating the collection of goods deliverable plus the money paid at any future state $s \in S$. Therefore, the asset market is summarised by an $((L+1) S) \times J$ matrix:

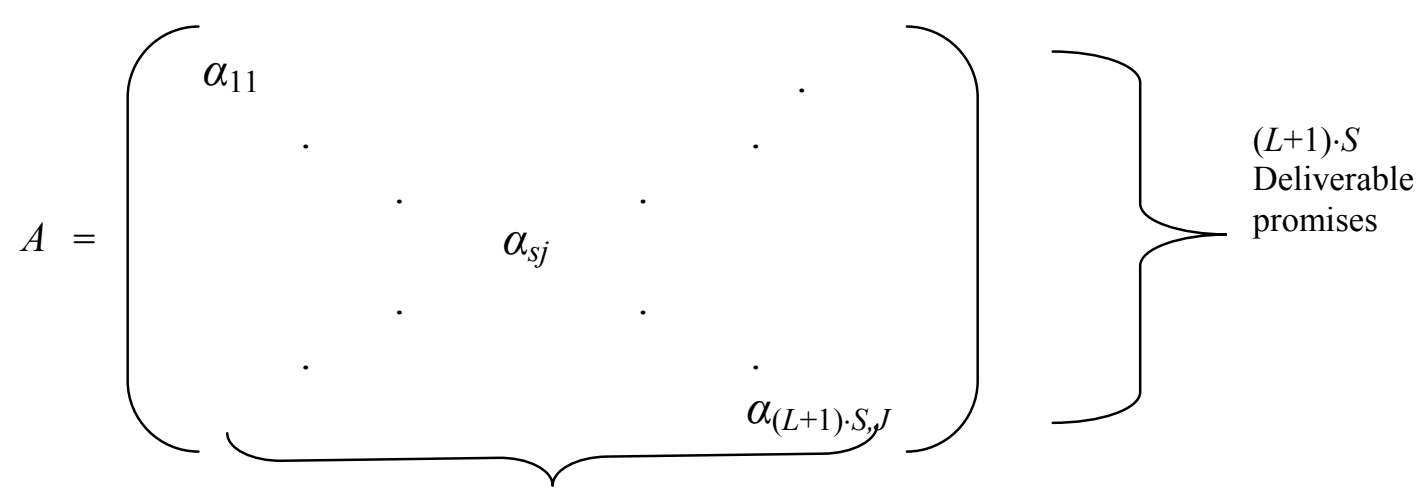

$J$ assets

All deliveries are made in money. When the assets promise commodities the seller of the assets delivers the money equivalent of the value of the agreed commodities at their spot prices at the relevant state. The set of assets that are admissible is quite general, ${ }^{(12)}$ however I restrict my attention to the 'standard' asset matrix without loss of generality.

In the model a government bond is an asset, which promises money in all states, ie $A_{s m}^{j}=1, \forall s \in S$. Moreover, a financial asset is one with $A_{s l}^{j}=0, \forall l \in L, s \in S$. The column rank (ie the number of linearly independent columns) of $A$ is critical since it describes the structure of the asset market. Whenever $\operatorname{rank}|J|=\operatorname{rank}|S|$ the capital markets are said to be complete whereas when $\operatorname{rank}|J|<\operatorname{rank}|S|$ markets are incomplete. The case when some assets are missing is the most interesting one because in addition to its realism it allows for the study of financial innovation, government intervention and numerous other interesting macroeconomic phenomena.

Furthermore,

(A6) $A^{j} \neq 0, \forall j \in J$.

\footnotetext{
${ }^{(12)}$ Quantity constraints, limited participation and collateral can be incorporated within this framework without affecting the existence of equilibria (see Section 8).
} 
(ie no asset makes zero promises.)

(A7) $A^{j} \geq 0, \forall j \in J$.

(ie asset payoffs are non-negative.)

Finally, agents do not hold positive endowments of assets and thus all asset transactions are short sales.

In the spirit of perfect competition asset prices facing individuals agents are fixed. Let $b_{j}^{h} \equiv$ amount of money sent by agent $h$ in the market of asset $j$. Also, let $q_{j}^{h} \equiv$ promises sold of asset $j$ by agent $h \in H$. In equilibrium, at positive levels of trade $0<\theta_{j}<\propto$,

$$
\theta_{j}=\frac{\sum_{h \in H} b_{j}^{h}+\sum_{b \in B} b_{j}^{b}}{\sum_{h \in H} q_{j}^{h}+\sum_{b \in B} q_{j}^{b}},
$$

for $j \in J, h \in H, b \in B$. All the asset markets meet contemporaneously; hence cash obtained from the sale of asset $j$ cannot be used for the purchase of another asset $j^{\prime} \neq j$. Thus, the volume of trade in the asset market is affected by the overall liquidity of the economy. Thus monetary policy interacts with asset markets and influences asset prices. ${ }^{(13)}$

\subsection{Money and credit markets}

Fiat money is the stipulated means of exchange. All commodities can be traded for money, and (as noted) all assets deliver exclusively in money. Money can be either inside or outside (Gurley and Shaw (1960)). At the outset NBPS and banks hold net monetary assets - outside money - (ie as if they hold central bank liabilities). Inside money is credit created by the banking sector through the credit markets in period 0 via monetary policy and is accompanied by debt. Commercial banks receive central bank money as an asset but simultaneously incur a debt liability. In turn, commercial banks lend to the non-bank private sector. This represents an asset of the commercial bank and thus a liability of the non-bank private sector. The net assets of the private sector as a whole remain unchanged.

Cash-in-advance is required for any purchase. ${ }^{(14)}$ To buy a commodity or bond an agent must pay cash, which he can obtain from his private monetary endowments, or out of inventories from previous market transactions. Since fiat money is the stipulated means of exchange, transactions

\footnotetext{
${ }^{(13)}$ Since liquidity (ie cash in circulation) affects asset prices, the asset price inflation channel of monetary policy is present in the model.

${ }^{14)}$ One should not interpret the cash-in-advance as a currency constraint but rather as a liquidity constraint. This is so because, I could have assigned liquidity parameters for each commodity and use the ensuing liquidity constraints. The main feature of the cash-in-advance constraint is the asymmetry of liquidity capabilities of the postulated means of exchange as compared with the rest of commodities. For example, Grandmont and Younes (1972) assign a liquidity parameter in the cash-in-advance constraint.
} 
in each market have a convenient physical interpretation according to which money is traded for equal value of commodities or bonds. If interest rates are positive the necessity to have cash in order to purchase commodities invalidates the 'classical' dichotomy between the real and financial sectors of the economy.

A market is regarded as a symmetric exchange between two instruments. In standard Arrow-Debreu terminology, a market bears only one name. Since in this model money is always one of the instruments, each market can be given a single name. But one could easily imagine other markets (eg for credit card purchases) where neither side was cash; for more discussion see Dubey, Geanakoplos and Shubik (2000). Just as agents cannot 'sell' money they do not have, in the model they cannot sell commodities they do not have. The only exception is credit markets, where agents are allowed to write their own promises (bonds). ${ }^{(15)}$

Money enters the economy in three ways. First, it may be present in the private endowments of agents and commercial banks. Agent $h \in H$ has an endowment $m_{s}^{h}$ of money, for each $s \in S^{*}$ and commercial banks have initial capital endowment $e_{s}^{b}$, for each $s \in S^{*}$. Second, when government and/or the central bank purchases commodities and/or bonds with currency, it injects money in the economy. Third, when the government (perhaps through the central bank) repays previously issued government bonds, it also injects money in the economy. The channel by which money enters the economy influences the effect the money has on the economy, as we shall see in greater detail below. Money exits the system in two ways: bonds from the NBPS and payment on bonds (promises) sold to the government and/or the central bank.

Two kinds of bond (equivalently credit or loan) markets can be distinguished. Short-term (intraperiod or overnight) bonds promise 1 unit of fiat money at the end of the same period in which they are taken. Long-term (interperiod) bonds promise 1 unit of money at the beginning of the next period, but after the next short loan begins. ${ }^{(16)}$ Note that long-term loans can be thought of as one-period zero coupon bonds.

By rolling over a long loan to the next short loan to the next long loan, agents can borrow against any future time period. Let $r_{s}, \bar{r}$ be the interest rates on short and long-term loans respectively. An agent who borrows $\varepsilon$ in the intraperiod (interperiod) loan market owes $\left(1+r_{s}\right) \varepsilon((1+\bar{r}) \varepsilon)$ at the end of state $s \in S^{*}$ (at the beginning of period 1). Agents regard the interest rates as fixed.

The central bank has exogenously specified positive quantities of money $\left(M^{G}\right)$, which it auctions off in the interbank bond market. The bank also sells bonds $\left(\mu^{G}\right)$ in the same market.

NBPS is permitted to deposit money at the commercial banks where they earn the same interest rate as the banks charge.

\footnotetext{
${ }^{(15)}$ An alternative interpretation of the cash-in-advance constraint is that financial markets clear immediately whereas commodity markets adjust sluggishly.

${ }^{(16)}$ Since each seller does not know what other promises each buyer has made and in addition the buyer has the option to default we are faced with a moral hazard problem. However, the moral hazard problem arises from opportunistic behaviour in a competitive environment.
} 
Note that one should not expect $r_{o}=\bar{r}$. Typically, the equilibrium term structure can be quite complex and depends on the multiple factors that influence the demand for money. ${ }^{(17)}$

NBPS is permitted to buy and sell bonds, ie to borrow and deposit money in the consumer credit markets. Let $\mu_{s}^{h}\left(\right.$ or $\left.\mu^{h}\right)$ be the amount of zero-coupon bonds issued by $h \in H$ or, equivalently, the amount of money agent $h$ chooses to owe on the short loan (or long loan). Let $d_{s}^{h}$ (or $\left.\bar{d}^{h}\right)$ be the amount of money that agent $h \in H$ spends on purchases of short-term (long-term) bonds. If all agents pay exactly what they owe, then

$$
\left(1+r_{s}\right)=\frac{\sum_{h \in H} \mu_{s}^{h}}{\sum_{h \in H} d_{s}^{h}+\sum_{b \in B} m_{s}^{b}} \quad, \quad \forall s \in\{0,1, \ldots, S\}
$$

and

$$
(1+\bar{r})=\frac{\sum_{h \in H} \bar{\mu}^{h}}{\sum_{h \in H} \bar{d}^{h}+\sum_{b \in B} \bar{m}^{b}},
$$

where, $m_{s}^{b}\left(\bar{m}^{b}\right)$ is the amount of credit that commercial banks extend which is also subject to their regulatory capital-adequacy ratio as specified by the regulator.

\subsection{Default}

Under the presence of uncertainty and agent optimisation, default can be either strategic or due to ill fortune. Someone may default because the penalty is too lenient (ie strategic default) or because he does not have the necessary means (ie economic ill fortune). Lenders cannot distinguish whether default occurs because the debtors are unable to honour their contractual obligations or they chose to do so even though they have the necessary resources. The default penalties are proportional to the level of default. They exist to induce debtors to honour their obligations when they are able to do so, and to refrain from making promises that they know they will not honour in the future.

Let $\Omega=\{N\} \cup\{J\}=\left\{0^{*}, \overline{0}, 0,1, \ldots, S\right\} \cup\{1, \ldots, J\} . \Omega$ is the set of all credit markets (including the interbank) and secondary asset markets $\left(0^{*} \equiv\right.$ interbank, $\overline{0} \equiv$ long - term credit market, $0,1, \ldots, S \equiv$ short - term credit market $)$. Let us define $D_{s \omega}^{h}=\left(1-v_{s \omega}^{h}\right) \mu_{s}^{h}\left(D_{s \omega}^{b}=\left(1-v_{s \omega}^{b}\right) \mu^{b}\right)$ where $v_{s \omega}^{h}\left(v_{s \omega}^{b}\right)$ is the rate of repayment by households (banks). $D_{s \omega}^{h}$ is the nominal value of debt due to default either in the credit markets (analogously in the asset market or deposits and interest rate obligations). In practice, default penalties and the bankruptcy code depend normally on the nominal values of debt and are adjusted at discrete intervals as the general level of prices

\footnotetext{
${ }^{(17)}$ Both the expectations and the liquidity preference hypothesis of the term structure of interest rates jointly determine the term structure of interest rates.
} 
increases. In the model, nominal values are deflated so as to penalise households and banks on 'real' default. ${ }^{(18)}$

The parameters $\lambda_{s \omega}^{h}\left(\lambda_{s \omega}^{b}\right)$ represent the marginal disutility of defaulting for each 'real' dollar on assets or loans in state $s$. Therefore, the payoffs to the NBPS and commercial banks will be respectively $\forall s \in S^{*}$,

$$
\Pi_{s}^{h}\left(x_{s}^{h},\left(D_{s \omega}^{h}\right)_{\omega \in \Omega}, p_{s}\right)=u_{s}^{h}\left(x_{s}\right)-\frac{\sum_{\omega \in \Omega} \lambda_{s \omega}^{h}\left[D_{s \omega}^{h}\right]^{+}}{p_{s} g_{s}}
$$

and

$$
\Pi_{s}^{b}\left(\pi_{s}^{b},\left(D_{s \omega}^{b}\right)_{\omega \in \Omega}, p_{s}\right)=u_{s}^{b}\left(\pi_{s}^{b}\right)-\frac{\sum_{\omega \in \Omega} \lambda_{s \omega}^{b}\left[D_{s \omega}^{b}\right]^{+}}{p_{s} g_{s}}
$$

where $g_{s}$ is the price index for a basket of goods which serves as the price deflator for the bankruptcy penalty and

$$
[c]^{+} \equiv \max [0, c]
$$

The specification of default captures the idea (first introduced by Shubik and Wilson (1977)) that utility decreases monotonically in the level of default because it becomes more expensive to default. ${ }^{(19)}$ In equilibrium, agents equalise the marginal utility of defaulting (ie increased consumption) with the marginal disutility of the bankruptcy penalty. Thus, expected rates of delivery of interbank, long-term, short-term loans in $s=0$ and for all $s \in S$, for assets, and analogously for deposits $R=\left(\widetilde{R}_{s}, \bar{R}_{s}, R_{s}, R_{s j}, \widetilde{R}_{d s}, \bar{R}_{d s}, R_{d s}\right) \forall s \in S^{*}$ and $j \in J$, are equal to actual rates of delivery in equilibrium. ${ }^{(20)}$ This idea is precisely the crucial ingredient of the model. It allows default as an equilibrium outcome without necessarily destroying the orderly functioning of the financial system.

\footnotetext{
${ }^{(18)}$ Complicated structures of default penalties can be incorporated into the model as long as concavity of the payoff function is maintained. For further details on this topic see Dubey and Geanakoplos (1992) and Dubey, Geanakoplos and Shubik (2000). Without loss of generality, a simple specification is used that assumes penalties are adjusted instantaneously following changes in the price level.

${ }^{(19)}$ Alternatively, I could have modelled default penalties by subtracting resources according to the $\lambda$ 's from the budget constraints of the agents. However, this technique is more complicated since the marginal disutility of default is not constant but directly affects the marginal rates of substitution of commodities as can be seen from the first order conditions. Detailed exposition of this more general default modelling methodology can be found in Tsomocos (2002) where I treat this default specification as a special case of generalised default penalties. ${ }^{(20)}$ For a definition of rates of delivery and a necessary assumption that these expectations should satisfy, see Section 5.
} 


\subsection{Capital requirements}

The regulator sets the banks' minimum capital requirements. Given that the assets of the commercial banks consist of loans (including interest rate payments) and investments in marketable assets, the capital requirement constraint becomes,

$$
k_{b s} \leq \frac{e_{s}^{b}+\sum_{h \in H} u_{b}^{h}+c_{s}^{b}}{w_{s s}^{b}(\eta, \sigma) R_{s} m_{s}^{b}\left(1+r_{s}\right)+w_{s \overline{0}}^{b}(\eta, \sigma) \bar{R}_{s} \bar{m}^{b}(1+\bar{r})+\sum_{j \in J} w_{s j}^{b}(\eta, \sigma) R_{s j}\left(p_{s} A_{s}^{j}\right)\left(\frac{b_{j}^{b}}{\theta_{j}}\right)+w_{s 0^{*}}^{b} \widetilde{R}_{d s}(1+\rho) d^{b}},
$$

$\forall s \in S, b \in B$

and

$$
k_{b 0} \leq \frac{e_{0}^{b}+\sum_{h \in H} u_{b}^{h}+c_{0}^{b}}{w_{00}^{b}(\eta, \sigma) R_{0} m_{0}^{b}\left(1+r_{0}\right)+w_{0 \overline{0}}^{b}(\eta, \sigma) \bar{m}^{b}(1+\bar{r})+\sum_{j \in J} w_{0 j}^{b}(\eta, \sigma)\left(p_{s} A_{s}^{j}\right)\left(\frac{b_{j}^{b}}{\theta_{j}}\right)+w_{00^{*}}^{b}(\eta, \sigma)(1+\rho) d^{b}},
$$

for $s=0$,

where, $w_{0 s}^{b} \equiv$ risk weights for short-term loans, $w_{s \overline{0}}^{b} \equiv$ risk weights for long-term loans,

$w_{s 0^{*}}^{b} \equiv$ risk weights for interbank loans, $w_{s j}^{b}, \quad \forall j \in J \equiv$ risk weights for marketable assets, $\eta \equiv$ set of macrovariables, and $\sigma \equiv$ choice variables of the NBPS and commercial banks. ${ }^{(21)}$ In addition, $\sum_{h \in H} u_{b}^{h} \equiv$ initial equity of commercial banks and $c_{s}^{b} \equiv$ capital adjustment. Thus, commercial banks decide on any capital adjustment jointly with any restructure of their asset portfolio so as to satisfy their capital requirements constraint. Banks may not necessarily hold the same capital since precautionary capital over and above the regulatory minimum can vary across banks. Note that credit requirements in the first period are calculated with respect to the realised asset deliveries in equilibrium and not the expected ones.

The impact of regulatory policy in the model is similar to monetary policy, since it affects credit extension, although it operates through different channels.

Finally, it should be noted that increased default reduces utility but it may also have an indirect counterbalancing effect. If risk weights were countercyclical, higher defaults, as would occur in a recession, would lead banks to reduce their risk weights in the expectation that future economic conditions will improve. In turn, if capital constraint were binding, lower risk weights would allow for an increasing credit extension that reduces interest rates and thus facilitates

(21) The risk weights may or may not be invariant. For example, they may be time varying and dependent on other macrovariables or choices of investors and/or banks. Catarineu-Rabell, Jackson and Tsomocos (2001) examine the case where they depend on NBPS default either procyclically or countercyclically. 
transactions. ${ }^{(22)}$ Thus, utility may very well increase if the latter effect dominates the former. In such a situation capital requirements may be thought of as a built-in-stabiliser of the economy.

\subsection{The commodity markets}

Commodity prices $p_{s l}$ are taken as fixed by the agents. Let $b_{s l}^{h} \equiv$ amount of fiat money sent by agent $h$ to trade in the market of commodity $s l \in L$. In addition, let $q_{s l}^{h} \equiv$ amount of good $l$ offered for sale at state $s$ by agent $h$. NBPS and government cannot sell commodities they do not own, so $q_{s l}^{h} \leq e_{s l}^{h}$. Let $b_{s l}^{G} \equiv$ amount of fiat money that the government puts up to buy commodity $s l \in L$. Government expenditures are taken as exogenous and are meant to capture fiscal policy. In equilibrium, at positive levels of trade, $0<p_{s l}<\infty$,

$$
p_{s l}=\frac{\sum_{h \in H} b_{s l}^{h}+b_{s l}^{G}}{\sum_{h \in H} q_{s l}^{h}} .
$$

All markets meet simultaneously; hence cash obtained from the sale of commodity $l$ at state $s$ cannot be used for the purchase of another commodity $l$ at the same state. This institutional arrangement is the fundamental feature of the model that captures the importance of liquidity constraints and the transaction demand for cash. Liquidity constraints should not be viewed as market imperfections but rather as the intrinsic characteristic that distinguishes commodities from liquid wealth. ${ }^{(23)}$

\subsection{Stocks, flows and liquidity constraints}

In the abstract Arrow-Debreu model it is difficult to distinguish stocks and flows, especially when public production is involved. Even when they can be distinguished formally, there is no importance in the distinction; one might as well assume that every good is bought and sold each period. Similarly in the Lucas (exchange economy) model, agents are required to sell everything in each period, so there can be no distinction between stocks and flows.

However, in contrast, in this model the sales $q_{s l}^{h}$ of commodities by agents are endogenous; agents are not required to put anything up for sale. Indeed, since sales equal purchases in equilibrium, the total quantity of sales is a good measure of aggregate economic activity.

$Y_{s}=\sum_{l \in L} \sum_{h \in H} p_{s l} q_{s l}^{h}$ and $\bar{y}_{s}=\sum_{l \in L} \sum_{h \in H} q_{s l}^{h}$ are the nominal and real incomes of agents at state $s \in S^{*}$ respectively. They are endogenous variables determined in the model. ${ }^{(24)}$

\footnotetext{
${ }^{(22)}$ See Catarineu-Rabell, Jackson and Tsomocos (2001).

(23) This price formation mechanism first introduced by Shapley and Shubik (1977), is an equilibrium condition. Its accounting clarity allows cash flows in the economy to be traced precisely.

${ }^{(24)}$ The real income is an arbitrary number since it depends on the units in which we measure goods. Some policy changes, however, may increase $\bar{Y}_{s}$ no matter how we measure the units.
} 
As was emphasised in the introduction, the process-oriented nature of all transactions assigns to them a physical interpretation and preserves accounting clarity. The receipts from sales of goods and assets cannot be used contemporaneously for purchases. This mismatch between cash outflows and inflows in an agent's budget is intermediated by the credit markets. The same argument applies for commercial banks and their corresponding asset-liquidity mismatch that the interbank credit market intermediates. Therefore, the endogenous determination of interest rates on the various credit markets may be such that NBPS and/or commercial banks are liquidity constrained. The credit channel of the model manifests itself in the extent to which liquidity constraints are binding and generate real effects in consumption. In particular, the repercussions of financial crises require the ability to distinguish between stocks and flows. Financially unstable regimes affect the flows of economic transactions and only after a lag is the impact on the stock variables of the economy observed. For example, a liquidity crisis first reduces the volume of trade and subsequently, perhaps, reduces the profitability of the banking sector.

\subsection{Commercial banks}

Commercial banks enter the model because of their importance both for the transmission of monetary policy and for financial stability. The risk profiles of commercial banks have an effect on both liquidity and the credit expansion of the economy. Consequently, the money supply multiplier of the economy depends on the portfolio of the banking sector. Thus, equilibrium outcomes of the economy and the effectiveness of monetary policy depend on the banking sector.

Let $b \in B=\{1, \ldots, B\}$ be the set of commercial banks. We assume:

(A8) perfectly competitive banking sector (ie commercial banks take interbank interest rates and asset prices as given.)

(A9) perfect financial intermediation (ie no market imperfections with respect to information and participation in the capital and credit markets.)

An important consequence of (A8) and (A9) is that there is no margin between borrowing and lending rates.

Recall that each bank has an initial capital endowment and its risk profile is described by a concave, monotonic and continuous utility function:

$u^{b}=R_{+}^{s *} \rightarrow R$

where, $u^{b}\left(\pi_{0}^{b}, \pi_{1}^{b}, \ldots, \pi_{s}^{b}\right)$ represents the utility to a bank $b$ when its final monetary holdings in $s \in S^{*}$ 
As can be seen from the market structure of the model, at the beginning of period zero an equity market operates in which banks issue equity to investors. Shares of ownership of the bank are determined on a prorated manner according to the formula, ${ }^{(25)}$

$$
s_{b}^{h}=\frac{u_{b}^{h}}{\sum_{h \in H} u_{b}^{h}}
$$

where, $u_{b}^{h} \equiv$ amount of money offered by $h$ for ownership shares of bank $b \in B$.

Finally at $t=1$ the profits of commercial banks are liquidated and distributed back to the individual owners. This way I close the model.

An important phenomenon that now appears is that not all members of the NBPS will defray their loans and all banks might honour their contractual obligations. The different risk-attitudes and the bankruptcy penalties imposed on defaulting banks make this compatible with equilibrium.

A simplified version of the bank's balance sheet is:

$($ Deposits $)+($ Equity $) \equiv($ Reserves $)+($ Loans $)+($ Interbank Deposits $)+($ Asset Investments $)$.

Deposits are taken from and loans are made to other commercial banks and the NBPS. Equity consists of the initial capital endowment, initial equity and capital adjustments. Investments in marketable assets may appear in either the asset or the liability side of the balance sheet depending on whether the bank is long or short on a particular asset.

\subsection{Interbank credit market}

The central bank conducts its monetary policy through OMOs in the interbank market. There is interbank lending and borrowing. This market establishes interbank linkages and in the case of default may cause a domino effect. Since perfect financial intermediation (ie there is no margin between borrowing and lending rates) is assumed default is prorated among all the lenders (ie aggregate default is allocated among all banks according to the percentage of loans they have extended). Thus, contagion and interbank linkages are equilibrium phenomena that manifest themselves via perfect intermediation and do not necessarily require an oligopolistic (or monopolistic competition) market structure or other market inefficiencies or failures.

The interbank interest rate is established in equilibrium at positive levels of trade,

$$
(1+\rho)=\frac{\sum_{b \in B} \mu^{b}+\mu^{G}}{\sum_{b \in B} d^{b}+M^{G}}
$$

\footnotetext{
${ }^{(25)}$ When the model extends more than two periods then dilution of the existing ownership structure can be introduced by allowing retrading of the ownership shares of the banks. However, this extension would be more appropriate after I introduce production into the model and analyse the capital structure of banks and firms.
} 
where, $\mu^{b} \equiv$ amount of zero-coupon bonds issued by bank $b$, (or equivalently the amount of money bank $b$ chooses to owe in the interbank credit market), $d^{b} \equiv$ amount of money that bank $b$ deposits, (or equivalently the amount of money that bank $b$ spends on purchases of bonds). Similarly, $\mu^{G} \equiv$ amount of zero-coupon bonds issued by the central bank and $M^{G} \equiv$ central bank money supply or equivalently the amount of money the central bank spends on purchases of bonds. ${ }^{(26)}$

In practise the monetary authorities use the repo market to set interest rates and then commercial banks participate in the interbank market. Both markets are collapsed into one because the monetary transmission mechanism remains the same apart from the size of credit extension in the context of this model. The separation of these markets becomes necessary only when the focus is on the transmission mechanism of monetary policy.

Both in the NBPS credit markets and the interbank market default is allowed; so bonds and currency are not perfect substitutes. Equities and bonds are the only instruments agents are allowed to sell without owning. Essentially any agent can write his own promise, which then becomes a bond. However, he is limited in how many he can issue by the bankruptcy penalties that prevent him from going arbitrarily short. Assets, bonds and money can be inventoried from period 0 to period 1 ; they are the only stores of value in the model. None of these instruments gives direct utility to the agents. Utility is derived only through the results of transactions they facilitate.

\section{The budget set}

\section{$4.1 \quad N B P S$}

Macrovariables $\left(\eta=\left(p, \rho, r_{s}, \bar{r}, \theta, R\right)\right)$ are determined in equilibrium and every agent takes them as given. Agents are perfect competitors and therefore price takers. The choices of every member of the NBPS, $h \in H$, obey the following constraints. ${ }^{(27)}$

For $t=0$,

short-term + long-term deposits $\leq$ initial private monetary endowment.

Expenditures for commodities, equities and banks' shares of ownership $\leq$ money at hand + borrowed money in the short and long-term credit markets.

Sales of commodities $\leq$ endowments of commodities.

Short-term loan repayment $\leq$ money at hand + receipts from sales of commodities and equities + deposits and interest repayment.

Consumption $\leq$ initial endowment - sales + purchases.

\footnotetext{
${ }^{(26)}$ Instead of conducting OMOs, the central bank could determine the interest rate letting borrowing and lending with commercial banks equilibrate the market. In fact, this is the current practice of implementing monetary policy. The crucial point is that the central bank has one degree of freedom and therefore can use only one of the two policy instruments.

(27) The formal characterisation of the NBPS's and commercial banks' budget set is provided in Appendix I.
} 
$\forall s \in S$

short-term deposits in state $s \leq$ money at hand + initial private monetary endowment in state $s$.

Expenditures for commodities, equities deliveries and long-term loan repayments $\leq$ money at hand + short-term loan in state $s+$ long-term deposits and interest repayments.

Sales of commodities $\leq$ endowments of commodities.

Short-term loan repayment in state $s \leq$ money at hand + receipts from equities deliveries, sales of commodities, deposits and interest repayment, distribution of commercial banks' profits. $\quad\left(9^{\mathrm{h}}\right)$

Consumption $\leq$ initial endowment - sales + purchases.

\subsection{Commercial banks}

Similarly the choices of a commercial bank $b \in B$, obey the following constraints:

For $t=0$,

deposits in the interbank market $\leq$ initial capital endowment.

Credit extension in the short and long-term market + expenditures for equities $\leq$ money at hand + interbank loan + receipts from ownership shares' sales.

Short-term deposits and interest repayment + capital adjustment $\leq$ money at hand + short-term loans repayment + receipts from equities sales.

Capital requirements constraint in period 0 .

$\forall s \in S$,

credit extension in the short-term credit market in state $s+$ long-term deposits and interest repayment $\leq$ money at hand + long-term loan repayment + initial capital endowment in state $s \equiv$ period 0 profits.

Capital adjustment + short-term deposits and interest repayment + interbank loan repayment + expenditures for equities deliveries $\leq$ money at hand + money received from equities payoffs + interbank deposits and interest repayment + short-term loan repayment.

Capital requirements constraint in state $s$.

Profits are the difference between the right-hand side and left-hand side of $\left(6^{\mathrm{b}}\right)$.

Note that since the banking sector is perfectly competitive loan repayments are made proportional to the credit issued by each commercial bank relative to the aggregate credit issued by the entire banking sector. 


\section{Equilibrium}

We say that ${ }^{(28)}\left(n,\left(\sigma^{h}\right)_{h \in H},\left(\sigma^{b}\right)_{b \in B}\right)$ is a monetary equilibrium with commercial banks and default (MECBD) for the economy $E=\left\{\left(u^{h}, e^{h}, m^{h}\right)_{h \in H},\left(u^{b}, e^{b}\right)_{b \in B}, A, M^{G}, \mu^{G}, m^{G}, b^{G}, k, \lambda\right\}$

iff:

(i)

$$
p_{s l}=\frac{\left(\sum_{h \in H} b_{s l}^{h}+m_{s}^{G}\right)}{\sum_{h \in H} q_{s l}^{h}}, \quad \forall s \in S, l \in L
$$

Condition (i) shows that all commodity markets clear (or equivalently that price expectations are rational).

(ii) $1+\rho=\frac{\left(\sum_{b \in B} \mu^{b}+\mu^{G}\right)}{\sum_{b \in B}\left(d^{b}+M^{G}\right)}$;

Condition (ii) shows that the interbank credit market clears (or equivalently that interbank interest rate forecasts are rational).

(iii) $\quad 1+r_{s}=\frac{\sum_{h \in H} \mu_{s}^{h}}{\left(\sum_{h \in H} d_{s}^{h}+\sum_{b \in B} m_{s}^{b}\right)}, \quad \forall s \in S^{*}$;

(iiia) $1+\bar{r}=\frac{\sum_{h \in H}^{-{ }^{h}}}{\left(\sum_{h \in H} d^{h}+\sum_{b \in B}^{-m^{b}}\right)}$;

Condition (iii) shows that all short-term (long-term) credit markets clear (or equivalently, that predictions of long-term interest rates are rational).

(iv)

$$
\theta_{j}=\frac{\left(\sum_{h \in H} b_{j}^{h}+\sum_{b \in B} b_{j}^{b}\right)}{\left(\sum_{h \in H} q_{j}^{h}+\sum_{b \in B} q_{j}^{b}\right)},
$$$$
\forall j \in J \quad ;
$$

${ }^{(28)}$ Recall that by assumption $p, \rho, r_{s} \bar{r}, \theta, R$ are different from 0 and $\infty$ in each component. 
Condition (iv) shows that asset markets clear (or equivalently, asset price expectations are rational).

$$
\sum_{h \in H} s_{b}^{h}=1, \forall b \in B
$$

Condition (v) shows that the equity market for the bank ownership clears (or equivalently bank equity shareholding expectations are rational).

$$
R_{s j}= \begin{cases}\frac{\sum_{h \in H \cup B}\left[v_{s j}^{h} p_{s} q_{j}^{h} A^{j}\right]}{\sum_{h \in H \cup B}\left[p_{s j} q_{j}^{h} A^{j}\right]}, \text { if } \sum_{h \in H \cup B}\left[p_{j} q_{j}^{h} A^{j}\right]>0 & ; \forall s \in S, \quad j \in J . \\ \text { arbitrary } & , \text { if } \sum_{h \in H \cup B}\left[p_{j} q_{j}^{h} A^{j}\right]=0\end{cases}
$$

Condition (vi) shows that each asset buyer is correct in his expectation about the fraction of assets that will be delivered to him. ${ }^{(29)}$

(vii)-(xii) $R_{s}\left(\widetilde{R}_{s} \bar{R}_{s}, R_{d s}, \widetilde{R}_{d s}, \bar{R}_{d s}\right)=$

Conditions (vii)-(xii) show that the central bank and commercial banks are correct in their expectations about the fraction of loans that will be delivered to them. Similarly, the NBPS and commercial banks are correct in their expectations about the fraction of deposits and interest rate payments that will be delivered to them.

${ }^{(29)}$ Rates of delivery do not depend on anything that agents do themselves. Every agent receives the same rate of delivery. This is in accordance with the spirit of mass anonymous capital and credit markets. Otherwise, I would need to consider complicated strategic consequences, which unnecessarily complicate the model. However, even though the model does not include interpersonal moral hazard problems it deals with moral hazard in the aggregate. 
(a) $\sigma^{h} \in \underset{\sigma^{h} \in B^{h}(\eta)}{\operatorname{Arg} \max } \quad \Pi^{h}\left(x^{h}\right)$

(xiii)

and

(b) $\sigma^{b} \in \underset{\sigma^{b} \in B^{b}(\eta)}{\operatorname{Arg} \max } \quad \Pi^{b}\left(\pi^{b}\right)$.

Condition (xiii) shows that all agents optimise.

In sum, all markets clear and agents optimise given their budget sets. These are the defining properties of a competitive equilibrium.

If a monetary equilibrium with commercial banks and default (MECBD) exists, then default and financial fragility are established as equilibrium phenomena that arise in a standard equilibrium framework. Note, also that fiat money has positive value in a finite-horizon economy (for an extensive discussion on this see, Dubey and Geanakoplos (1992), Grandmont (1983), and Hahn (1965) who initially posed this problem). Government and regulator actions are exogenously fixed and are not deduced from optimising behaviour. Finally, no attempt is made to derive endogenously which assets will be traded in equilibrium in order to 'endogenise' market incompleteness.

Conditions (vi)-(xii) ensure that expected deliveries of assets, loans and deposits are equal to realised deliveries in equilibrium. However, the specification of expectations for inactive markets is arbitrary. Thus, the model does not rule out the situation when there is no trade. There are two ways around this (ie to exclude trivial equilibria ${ }^{(30)}$ ) in order to allow for comparative statics and policy analysis. The first has been introduced by Dubey and Shubik (1978) and adds an external agent that always supplies the asset and loan market with a minimal amount $\varepsilon$ and never abrogates his contractual obligation. The second has been suggested in Dubey, Geanakoplos and Shubik (2000) and offers an equilibrium refinement by forbidding 'overly pessimistic' expectations thus guaranteeing full delivery of 'small promises'. In other words, the situation in which no one is expected to honour even a 'small obligation' and therefore no one borrows or lends should be precluded. I adopt the first option and then let $\varepsilon \rightarrow 0$. It is more natural to allow for government intervention that establishes the functioning of the markets, rather than fixing expectations and so precluding potentially interesting phenomena of co-ordination failures and possibly discontinuous expectations in certain regimes of minimal trading. In addition, different expectation specifications may generate different prices and allocations.

Hereafter, I will assume in (vi)-(xii):

Inactive markets hypothesis: Whenever credit or asset markets are inactive (ie asset supply, credit extension or deposits are 0) the corresponding rates of delivery are set equal to 1 (ie honoured by government via an organisation such as FDIC).

\footnotetext{
(30) The examination of trivial equilibria merits further study whenever one tries to study financial innovation and endogenous generation of incomplete asset structures.
} 


\section{Orderly function of markets: existence}

Economic agents in the model are not required to trade. They always have the option to consume their own endowment in each state. Thus, there is no guarantee that they will demand money from any of the credit markets. If there is no demand for credit from NBPS, then it becomes ambiguous whether the interbank credit market will be active. It is ambiguous because while banks do not borrow to meet demand of NBPS, they may borrow to invest in the asset markets. And if there is no demand for liquidity in the economy then the asset market, in turn, will become inactive too. Indeed, in such a scenario, money will not have positive value and the nominal sector of the economy (monetary and financial) may be inactive and the corresponding markets may collapse.

Lucas circumvents the problem by forcing each agent to offer for sale his entire endowment, and then buy it back using money even if he himself wants to consume it. So, agents need money and liquidity by assumption since they cannot even consume their own endowment without it. The positive value of money is not an artefact of the infinite horizon but an outcome of the transaction mechanism postulated in the model (both cash-in-advance and mandatory sale of endowment). Thus positive trade in equilibrium is not a result, but rather given.

Although the assumption that each agent must sell all of his endowment seems innocuous, I will show that when combined with the 'representative agent' assumption (that all agents have the same preferences) it implies monetary policy neutrality.

This is so because lack of heterogeneity and forced sale of endowments imposes the classical dichotomy on the model (this is in contrast with a model where the validity of the classical dichotomy and the resulting quantity theory is determined endogenously in equilibrium, as shown by the existence argument, the propositions on the term structure of interest rates, and the quantity theory of money (Appendix III)).

When some monetary endowments, including the commercial banks' initial capital endowments, are positive then the term structure proposition shows that some interest rates must be positive. Otherwise, agents will be left at the end of period 1 with worthless paper money. Then by rational expectations and backward induction, the Hahn (1965) argument would obtain; money would have zero value. When interest rates are positive, agents will be willing to give up commodities even in period 1 to repay fully (or in part if they default) the loans they took from the banks for precautionary and speculative purposes as well as for transaction purposes.

However, when interest rates are positive (including the interbank interest rate) agents may not be willing to borrow from commercial banks (and similarly, commercial banks from the central bank). By borrowing 1 pound from the bank an agent can buy 1 pound worth of commodities. But he subsequently must sell $(1+r)$ pounds worth of commodities (ie more than one pound) in order to repay his loan. The agent will only agree to such a deal if the benefit of the increased utility from the additional commodities exceeds the utility loss from the commodities that he must sell to repay his loan. Similarly, the commercial banks will incur a decrease in 'profitability' equal to $£(1+\rho)$ for every pound they borrow in the interbank market whereas they will receive, if they extend the full amount of the loan, $£\left(1+r_{s}\right)($ or $£(1+\bar{r}))$. Thus, the transaction must be sufficiently profitable to undertake.

It must therefore be assumed that there are sufficient gains from trade available to agents to justify voluntary interest rate payments on grounds of rational behaviour. The formal description of the necessary gains to trade turns out to be surprisingly simple. Before providing the 
characterisation of that assumption it should be noted that dropping the artificial sell-all assumption of Lucas, it requires imposing minimum heterogeneity among agents, so that they want to trade. The simplest heterogeneity is intraperiod heterogeneity in endowments, so we require $L \geq 2$. The model thus differs from that of Lucas, who postulated $H=L=1$.

Debreu (1951) suggested that an allocation $\chi^{h} \in R_{+}^{S^{*} L}$ for each $h \in J \subset H$ is not $\delta$-Pareto efficient for $h \in J$ if it is possible to costlessly reallocate the commodity bundle (1- $\delta) \chi$ among those agents and make them all better off than they were at the original allocation. He called $\delta$ the coefficient of resource utilisation and interpreted it as a measure of how far a given allocation is from Pareto optimality. Dubey and Geanakoplos (1992) proposed that an allocation permits at least $\delta$-gains to trade if starting from that allocation, it is possible to make everybody better off in $J \subset H$ by transferring commodities, even though a fraction $\delta$ of the original bundle is lost.

Following, Dubey and Geanakoplos $(1992,1993)$ who first introduced the gains-from-trade hypothesis, and Geanakoplos and Tsomocos (2002) who used it in a related model, the definition and the hypothesis is modified to suit the present framework. Debreu threw out a fraction $\delta$ of the original bundle, but allowed for costless transfers. The whole of the original bundle is kept here instead, but a fraction $\delta$ of every transfer is thrown out.

The crucial insight of the gains-from-trade definition is that even if transactions are costly the higher utility that extra consumption would entail still makes them possible. This intuition can be stated formally in the following definition.

\section{Definition:}

Let $\left(\chi^{h}, \pi^{b}\right) \in R_{+}^{S^{*} \times(L+1)} \quad \forall h \in H, b \in B . \quad \forall \delta>0$, we will say that $\left(\chi^{1}, \ldots, \chi^{h} ; \pi^{1}, \ldots \pi^{b}\right) \in\left(R_{+}^{S^{*} \times L}\right)^{H} \times R_{+}^{S^{*} \times B}$ permits at least $\delta$-gains-from-trade in state $s$ if there exist trades $\tau^{1}, \ldots, \tau^{H} ; \tau^{1}, \ldots, \tau^{B}$ in $R^{L+1} \quad$ such that

1. $\sum_{h \in H} \tau^{h}+\sum_{b \in B} \tau^{B}=0$

2. (a) $\chi_{s}^{h}+\tau^{h} \in R_{+}^{L}, \quad \forall h \in H$

(b) $\hat{\pi}_{s}^{b}+\tau^{B} \in R, \quad \forall b \in B$

3. (a) $\Pi^{h}\left(\bar{x}^{h}\right)>\Pi^{h}\left(x^{h}\right), \quad \forall h \in H$

(b) $\Pi^{b}\left(\bar{\pi}^{b}\right)>\Pi^{b}\left(\pi^{b}\right) \quad$ where,

$$
\bar{x}_{t l}^{h}=\left\{\begin{array}{l}
\chi_{t l}^{h}, \quad t \in S^{*} \backslash\{s\} \\
\chi_{t l}^{h}+\min \left\{\tau_{l}^{h}, \tau_{l}^{h} /(1+\delta)\right\} \quad \text { for } l \in L \text { and } t=s
\end{array}\right\}
$$




$$
\bar{\pi}_{t}^{b}=\left\{\begin{array}{l}
\pi_{t}^{b}, t \in S * \backslash\{s\} \\
\pi_{t}^{b}+\min \left\{\tau^{b}, \tau^{b} /(1+\delta\} \quad \text { for } t=s\right.
\end{array}\right\}
$$

Note that when $\delta>0, \bar{x}_{l}^{h}<\chi_{t l}^{h}+\tau_{l}^{h}$, if $\tau_{l}^{h}>0$ and $\bar{x}_{t l}^{h}=x_{t l}^{h}+\tau_{l}^{h}$ if $\tau_{l}^{h} \leq 0$.

Also, $\bar{\pi}_{t}^{b}<\pi_{t}^{b}+\tau^{b}$, if $\tau^{b}>0$ and $\bar{\pi}_{t}^{b}+\tau^{b}$, if $\tau^{b} \leq 0$

Formally, the hypothesis I impose on the economy for sufficient gains from trade is:

G from T: $\forall s \in S$, the initial endowment $\left(e^{h}, e^{b}\right)_{h \in H, b \in B}$ permits at least $\delta_{s}$-gain to trade in state $s$, where

$$
\delta_{S}=\frac{\sum_{h \in H} m_{0}^{h}+\sum_{h \in H} m_{s}^{h}+\sum_{b \in B} e_{0}^{b}+\sum_{b \in B} e_{s}^{b}}{M^{G}} .
$$

The value of this ratio imposes an upper bound on the transaction costs incurred by agents from interest rate payments as can be seen from the term structure of interest rates proposition in Appendix III.

Condition ( $\mathrm{G}$ from $\mathrm{T}$ ) needs to be valid $\forall s \in S$ but not for $s=0$. Note that gains from trade should be present in the banking sector even though commercial banks do not consume. But since they are mutually owned and are liquidated at the end of period 1, rational agents expect these proceeds and incorporate them in the maximisation problem as can be seen from their budget constraint $\left(\left(9^{\mathrm{h}}\right)\right.$ of I.1). Also (G from T) precludes the case where $L=1, \forall s \in S^{*}$. Moreover, if the initial endowment is not Pareto optimal $\forall s \in S$, then holding all other government actions fixed as I vary $M^{G} \rightarrow \infty,(\mathrm{G}$ from $\mathrm{T})$ is automatically satisfied. ${ }^{(31)}$ The following theorem is proved in Appendix II.

Theorem 1: If in the economy $E=\left\{\left(u^{h}, e^{h}, m^{h}\right)_{h \in H},\left(u^{b}, e^{b}\right)_{b \in B}, A, M^{G}, \mu^{G}, m^{G}, b^{G}, \kappa, \lambda\right\}$,

(1) Gains from trade and inactive markets hypotheses hold,

(2) $M^{G}>0$,

(3) $\forall s \in S, \sum_{h \in H} m_{s}^{h}+\sum_{b e B} e_{s}^{b}>0$ and

(4) $\lambda>>0, \forall h \in H, b \in B$ then a MECBD exists.

${ }^{(31)}$ Alternatively, if $\sum_{h \in H} m_{s}^{h}=0$ and $\sum_{b \in B} e_{s}^{b}=0, \forall s \in S^{*}$ then G from $\mathrm{T}$ is automatically satisfied. See Shubik and Tsomocos (1992), for the argument of this case in a related model. 
The proof of this theorem resolves the Hahn problem and also the non-existence example of Hart (1975). Positive interest rates and bankruptcy penalties compactify the choice space by binding the potential transactions in the asset markets. Radner (1972), instead, imposed artificial bounds on asset trades to show existence. The proof of the theorem also indicates that as the aggregate 'outside' money becomes large then the necessary gains to trade for existence becomes arbitrarily large (ie the transaction cost caused by interest rate payments prohibits agents engaging in beneficial transactions). Therefore as 'outside' money grows, prices eventually rise, converging rapidly to infinity. When the ratio of outside to inside money becomes high enough so that equilibrium is unsustainable, hyperinflation occurs and trade collapses.

The main argument of the proof is that the monetary authority backs the fiat money present in the economy and gives it real value. By this is meant that 'money is an institutionalised symbol of trust'. ${ }^{(32)}$ The government compels the acceptance of money as a final discharge of debt. Investors use this 'government-backed' money because the benefit it gives them is greater than the interest rate loss. The interest rate can be thought of as the tax levied by the government for the supply of 'trust' and the 'system' that it establishes to safeguard trade in assets and commodities. This argument does not rest only on the cash-in-advance constraint but also on the presence of the government, standing ready to recoup loans, and the potential gains from trade. It is this triplet that guarantees existence and positive value of fiat money in the finite horizon.

The model has now been fully developed and its properties set out. It is therefore now possible to develop its implications for financial stability.

\section{Financial fragility, contagion and systemic risk}

\subsection{Financial fragility: concepts and definitions}

Numerous authors have tackled financial stability and at one level the term seems to be a familiar both from a theoretical as well as a practical viewpoint. However, very few attempts have been made to define and formally characterise it in an analytically rigorous way. Academics and policy-makers have offered various definitions. ${ }^{(33)}$ For example, Andrew Crockett (1997) argues that 'financial stability (refers) to the stability of the key institutions and markets that go to make up the financial system... stability requires (i) that the key institutions in the financial system are stable, in that there is a high degree of confidence that they continue to meet their contractual obligations without interruption or outside assistance; and (ii) that the key markets are stable, in that participants can confidently transact in them at prices that reflect fundamental forces and that do not vary substantially over short periods when there have been no changes in fundamentals'. Mishkin (1994) offers a more 'information-based' definition. 'Financial instability occurs when shocks to the financial system interfere with information flows so that the financial system can no longer do its job of channelling funds to those with productive investment opportunities'.

\footnotetext{
(32) Shubik (1999).

${ }^{(33)}$ A survey of these definitions and extensive discussion can be found in Bank for International Settlements (1998).
} 
The definition of financial fragility here is:

\section{When substantial default of a 'number' of households and banks (ie a liquidity 'crisis'), without necessarily becoming bankrupt, occurs and the aggregate profitability of the banking sector decreases significantly (ie a banking 'crisis').}

Formally, a MECBD $\left(n,\left(\sigma^{h}\right)_{h \in H},\left(\sigma^{b}\right)_{b \in B}\right)$ is financially fragile whenever

$$
D_{s \omega}^{h^{*}}, D_{s \omega}^{b^{*}} \geq \overline{\mathrm{D}}, \sum_{b \in B} \pi_{s}^{b} \leq \bar{\Pi}, \text { for }\left|H^{*}\right|+\left|B^{*}\right| \geq \bar{Z} \text {, and } s \in S^{*} \text { where } \bar{Z} \in(0,|H| \cup|B|] \text { and } \bar{\Pi}, \bar{D} \in R_{++} \text {. }
$$

Thus, financial fragility is characterised by both liquidity shortages and banking sector vulnerability. Moreover, it is allowed that the authorities (government and/or the central bank) determine the level of debt above which (and the profit below which), a financial environment becomes fragile. Also note that this definition hinges upon the welfare of the economy and its distributional consequences. The standard techniques and theorems of equilibrium theory can be readily applied. Equilibrium analysis is also amenable to comparative statics, for example, by varying capital requirement rules one can determine the expected default and the welfare effects of a crisis.

A natural question is why either one of the conditions is not sufficient by itself to constitute a financially fragile regime. Besides the empirical evidence provided in the introduction, increased default without reduced profitability might be an indicator of increased volatility and risk taking without necessarily leading to financial instability. For example, both the mean and variance of return might have risen. On the other hand, lower bank profitability without increased default might be an indicator of a recession in the real economy and not of financial vulnerability. It is the combination of both conditions that destabilises the financial system and may produce financial crises.

The following regimes are distinguished:

Liquidity 'crisis': A situation in which there exists substantial default of a 'number' of defaults (not necessarily bankruptcy and closure) both in the NBPS as well as the commercial banking sector.

Banking 'crisis': Together with substantial default of a 'number' of commercial banks, it is required that the profitability of the banking sector as a whole decreases significantly via interbank linkages.

Recession: In the context of an equilibrium model, a recession entails welfare losses by the aggregate NBPS sector. This highlights that what matters in a recession is the welfare loss due to reduced consumption, and not simply the loss of output.

This definition is sufficiently flexible enough to encompass most of the recent episodes of financial fragility. For example, the Japanese crisis may be thought of as an example of the Keynesian liquidity trap. The Mexican crisis of the early 1990s is a classic example of liquidity and banking crisis. The late 1990s east Asian crisis was characterised by a banking crisis and economic recession as well as extensive default. Finally, the Russian crisis, the Texas Banking crisis, and the US Stock Market crash of 1987 conformed to the characterisation of a financially 
fragile regime generated by liquidity shortages, extensive default and declines in bank profitability.

In summary, the information-based definition of Mishkin and the institutionally oriented one offered by Crockett encompass crucial aspects of financial instability, however, they do not capture the main reason that policy-makers focus on instability, namely its welfare and distributional effects. In other words, their definitions highlight the inefficiency that a financially unstable regime generates but they are too general to be readily applicable for policy analysis. In addition, they do not address structural features (liquidity shortages and extensive default) that result in reduced bank profitability. Finally, widespread default and pronounced decrease in banks profitability eventually impairs markets and trade collapses altogether. Thus, a systemic financial crisis of the economy can be reinterpreted as a case of equilibrium non-existence.

\subsection{An example: changes in capital requirements}

A parameterised version of the model is now used to highlight the systemic effects of changes in capital requirements. The full details of these comparative statics are contained in Catarineu-Rabell, Jackson and Tsomocos (2001). The model consists of three sectors (the household, corporate and banking sectors), two time periods with two possible future scenarios, and a financial market with one single asset, assumed to be default free. The corporate sector can be thought of as firms, which both borrow from banks and sell marketable financial assets. The banking sector raises funds by borrowing from the interbank market and taking deposits from the household sector. These funds are used to make loans to the corporate sector and to buy marketable assets. Therefore, the financial structure of the economy is one of complete markets with two assets (loans and default free assets) and two states of nature (good and bad). Households and banks maximise consumption and profits respectively.

Comparative static experiments were carried out for different values of $\kappa$ (from $6 \%$ to $9 \%$ ). The results show that banks restructure their portfolio and invest more in the equity markets while at the same time they decrease their loans (ie they switch towards assets with lower risk weights to satisfy the higher capital requirement). The main reason that motivates substitution from loans to equities is that there is asymmetric default behaviour for loans and investments. In this simplified version of the model investors can default only on their loans to the bank. Thus, banks will respond to an increase in their capital requirements by diversifying away from the bank credit market towards the equities market, while still decreasing their total risk weighted assets.

Lower credit extension results in less liquidity in the system, and thus decreases banks' income through lower loan recoveries. This is rationally expected by the central bank, which will increase its default premium (and thus the interbank rate). Commercial banks increase their nominal debt to the central bank and increase their default rates in both states of nature; so, the average expected default rate of banks increases. This in turn reduces banks' profits while leaving household and investor sectors almost unaffected. In sum, tighter capital requirements generate financial fragility in the short run.

\subsection{Liquidity trap}

An extreme case of financial fragility is the well-known liquidity trap. An economy manifests a liquidity trap whenever financial fragility is coupled with monetary policy ineffectiveness. Put differently, when interest rates and prices do not react to monetary expansion default increases and consequently bank profitability is reduced. The Keynesian liquidity trap describes a situation in which monetary policy would not affect the nominal variables of the economy because 
consumers simply hold extra real money balances for speculative purposes. Given that interest rates are sufficiently low and they expect them to go up in the future, thus they do not invest into assets like bonds whose value will decrease when interest rates rise. Various authors provide explanations and formalisations of the liquidity trap, eg Hicks (1946), Tobin (1982), Grandmont and Laroque (1973), and Hool (1976) among others, based on non-rational expectations.

Dubey and Geanakoplos (1993) provide an alternative explanation based on the incompleteness of asset markets. As the money supply increases, investors spend most of their liquidity in the asset markets. Thus, the monetary expansion does not affect the real sector of the economy and prices remain bounded. So, in the economy, large amounts of money are carried over from period 0 to 1 via transactions in the asset market. The increased trading activity in the asset market results from combining assets whose payoffs differ only slightly in order to hedge against risks that are not directly insurable by a marketed asset. Indeed, the liquidity trap occurs when the underlying real economy does not possess equilibrium. ${ }^{(34)}$

In the present model the liquidity trap occurs via the same process. However, now commercial banks engage in large asset trades without changing the interest rates of the NBPS' credit markets. When the government employs an expansionary monetary policy, commercial banks do not channel the increased liquidity to the consumer credit markets but the asset market, and therefore increased activity is observed in asset transactions. So, commodity prices remain relatively unaffected along with the interest rates of NBPS credit markets.

The liquidity trap is observed in the interbank market and not in the rest of capital markets where trades are very large and prices naturally are affected. I summarise the previous argument in the following proposition. This is consistent with the intuition that it may be the case that the liquidity trap may occur in an isolated section of the capital markets and then impinges upon the rest of the nominal sector of the economy (eg Japan in the late 1990s). ${ }^{(35)}$

Proposition 1: Suppose that the economy has a riskless asset $A_{s m}^{j}=(1, \ldots, 1)$, (ie monetary payoffs in every state are equal to one) and $A_{s l}^{j}=0, \forall s \in S^{*}$ and $l \in L$. Also consider the case in which the underlying economy has no GEI. Then as $M^{G} \rightarrow \infty$, then

$\left[w_{s s}^{b}(\eta, \sigma) R_{s} m_{s}^{b}\left(1+r_{s}\right)+w_{s \overline{0}}^{b}(\eta, \sigma) \bar{R}^{b}(1+\bar{r})+\sum_{j \in J} w_{s j}^{b}(\eta, \sigma) R_{s j}\left(p_{s l} A_{s}^{j}\right)\left(\frac{b_{j}^{b}}{\theta_{j}}\right)+w_{s 0^{*}}^{b}(1+\rho) d^{b}\right] \rightarrow \infty$,

$\forall \mathrm{s} \in S^{*}$,

$w_{00}^{b}(\eta, \sigma) R_{0} m_{0}^{b}\left(1+r_{0}\right)+w_{0 \overline{0}}^{b}(\eta, \sigma) \bar{m}^{b}(1+\bar{r})+\sum_{j \in J} w_{0 j}^{b}(\eta, \sigma)\left(p_{s} A_{s}^{j}\right)\left(\frac{b_{j}^{b}}{\theta_{j}}\right)+w_{00^{*}}^{b}(\eta, \sigma)(1+\rho) d^{b} \rightarrow \infty$, for $s=0$,

$M^{G} /\left\|p_{o l}\right\| \rightarrow \infty$, and $\left(\sum_{h \in H} q_{j}^{h}+\sum_{b \in B} q_{j}^{b}\right) \rightarrow \infty$

Moreover, there exist

$\bar{D}$ and $\bar{\Pi}$ such that $D_{s \omega}^{h^{*}}, D_{s \omega}^{b^{*}}>\overline{\mathrm{D}}>0$ for some $b^{*} \in B, h^{*} \in H$, and $\sum_{b \in B} \pi_{s}^{b} \leq \bar{\Pi}$.

(34) The non-generic counterexample of GEI non-existence was first discovered by Hart (1975).

(35) Charles Goodhart made this point to me and it seems that the model accommodates it. 
Note that regulatory policy may 'break' this liquidity trap by imposing harsh capital requirements (or very high $w_{j}$ 's) and so, blocking excessive trading activity in the asset markets. Thus, extra liquidity will be available for credit extension and further gains to trade will be materialised by the NBPS due to lower interest rates.

\subsection{On bank runs}

One of the most noteworthy features of this definition is that it encompasses a wide spectrum of financially fragile regimes and treats the original result by Diamond and Dybvig as a special case. The situation that corresponds to default of the entire banking sector is tantamount to the Diamond-Dybvig inefficient outcome.

Diamond and Dybvig (1983) provided a model in which, in an inefficient equilibrium, commercial banks are unable to meet their withdrawal requirements when investors withdraw their deposits prematurely. Thus, banks default and this situation is interpreted as a bank run. This situation emerges in this model, however, because of bank heterogeneity. Intermediate situations where not all banks default or all depositors withdraw can also arise. Since default is pooled in the model, contagion occurs by the domino effect that default causes. For example, when Bank A defaults on Bank B, then Bank B is unable to meet his obligation to Bank C and so on. At the end, aggregate default is pooled and prorated among the participating agents and institutions in a market. Thus, one observes the contagious effects of adverse shocks to the economy and the mass anonymous nature of the market capturing the systemic risk involved in the case of default.

Proposition 2: Suppose that at a MECBD $\lambda$ 's $<<\infty, M^{G}<<\infty$ and $\kappa \leq 1$. Further, suppose $q_{j}^{b}=0, \forall b \in B$. Also, there exists $s \in S^{*}$ such that $\sum_{h \in H} \mu_{s}^{h}>\sum_{h \in H} d_{s}^{h}$. Then there exists $b \in B$ such that $D_{s \omega}^{b}>0$ in $s$.

Corollary 1 (Diamond-Dybvig): If together with the assumptions of the previous proposition we have $u^{b}=u, \lambda_{s}^{b}=\lambda$ and $\sum_{h \in H} \mu_{s}^{h}>\sum_{h \in H} d_{s}^{h}, \forall s \in S^{*}$ and $b \in B$, then $D_{s \omega}^{b}>0, \forall b \in B$ and $s \in S^{*}$.

This corollary captures the essence of the logic of the Diamond-Dybvig result, and highlights the special nature of their model and the importance of bank homogeneity. Moreover, all commercial banks are identical and default is pooled. Thus, all depositors rationally expect that the commercial banking sector will uniformly default on its obligations in all future states.

Corollary 2: Let the same assumptions of Corollary 1 hold and $k=1$. Then there exists

$\overline{\lambda^{b}}$ such that $D_{s \omega}^{b}=0, \forall b \in B, s \in S^{*}$. In addition, there exists $\bar{\lambda}^{h}$ such that $D_{s \omega}^{h}=0 \forall h \in H$.

Put differently, Corollary 2 underlines the importance of capital requirements for financial stability. Therefore, whenever credit is fully collateralised, the regulator guarantees future financial stability. But, there is a trade-off between financial stability and efficiency since stricter capital requirements generate higher interest rates and thus reduce efficient trade and limit banks' risk taking behaviour. Thus, $\lambda$ 's, $\kappa^{\prime}$ s and monetary policy should be studied contemporaneously when optimal regulatory policy is designed. 


\subsection{Constrained inefficiency}

Whenever markets are complete $M E C B D$ are efficient provided that all interest rates are zero, there is no bankruptcy and capital requirements are non-binding. However, the question that naturally arises is whether, given market incompleteness, equilibria are constrained efficient (or second best). ${ }^{(36)}$ In view of the existence of active monetary and regulatory policy for crisis prevention and management, the answer is tantamount to justifying (or not) intervention. Constrained efficiency points in fixing the structure of the economy whereas constrained inefficiency suggests making adjustments within the structure and still improve the efficiency of the economy. The short and medium-term macroeconomic consequences of capital requirements point towards the examination of constrained efficiency of the economy. Indeed, Blum and Hellwig (1995) in an IS-LM framework argue that capital adequacy regulation may reinforce macroeconomic fluctuations. What produces their result is increases in non-performing loans that may lead banks to reduce credit extension and thus industry investment declines. However, one may wonder whether with diversified bank portfolios this result holds. It may very well be the case that banks switch their investment to other asset classes and firms search for funds in the asset markets. The following theorem indicates that the Blum and Hellwig argument is robust in this more general framework.

Theorem 2 : Each MECBD $\left(n,\left(\sigma^{h}\right)_{h \in H},\left(\sigma^{b}\right)_{b \in B}\right)$ with $\lambda=+\infty$ and binding capital requirements (ie equations $\left(4^{b}\right)$ and $\left(7^{b}\right)$ ) is constrained inefficient among the allocations that are feasible and, given the period 0 optimal choices, it satisfies the budget constraints in all states of period 1 at the old equilibrium prices.

Therefore, if the government or the regulator intervened in period 0 through transfers, taxation or by modifying the capital requirements ${ }^{(37)}$ of the economy, it could Pareto improve the original equilibrium. Of course, such intervention presupposes the same period 1 equilibrium prices as in the old equilibrium. However, as the theorem asserts, such a Pareto improving intervention assumes neither bankruptcy nor binding capital requirements in the original equilibrium. When bankruptcy is allowed then a similar trade-off exists as that between severity of the bankruptcy code and efficiency, ${ }^{(38)}$ but in this context the trade-off is between regulatory policy and efficiency. The upshot of this discussion is that there exists optimal regulatory policy, which depends on the particular parameters of the economy. Thus, the dynamic adjustment of capital requirements needs context specific knowledge of the economy and most probably needs to be tailor made for each particular case. This is of great importance for the design of regulation.

\footnotetext{
(36) The pioneering paper on the subject of constrained inefficiency in incomplete markets with numeraire goods was written by Geanakoplos and Polemarchakis (1986).

${ }^{(37)}$ Indeed, Catarineu-Rabell, Jackson and Tsomocos (2001), in the context of a parameterised simulation, establish the optimal regulatory system (ie neutral, procyclical, countercyclical risk-weights) under different policy criteria (ie bank profit maximisation, welfare maximisation and default minimisation).

${ }^{(38)}$ See Dubey, Geanakoplos and Shubik (2000), for an example of this trade-off. But no general theorem has yet been provided on this.
} 


\section{Concluding remarks}

In this paper an attempt has been made to provide a rigorous framework for analysing contagion and financial fragility. A general equilibrium model with incomplete asset markets, money and default has been built. A commercial banking sector that maximises profits subject to capital requirements and a formal definition of financial fragility are also included. The orderly functioning of markets is established, and the existence of equilibrium is thus shown to be compatible with default and financial fragility. The possibility of a liquidity trap is demonstrated. A version of the Diamond-Dybvig result occurs in equilibrium under certain conditions. Equilibria are constrained inefficient.

Within this framework, which displays several crucial characteristics of the financial system in its current form, it has been possible to show how financial fragility manifests itself in the continuum, and may not precipitate a financial crisis if the appropriate measures are adopted. Thus, active regulatory policy may (as Theorem 2 shows) be used to improve welfare and alter the distributional effects of financial fragility.

The framework is also capable of development so as to explore certain other issues.

The endogenous determination of the value of collateral during periods of fragility is an important variable in crisis prevention. The size and composition of collateral (eg pyramiding or tranching) affects the magnitude of the optimal bankruptcy penalty and capital requirements. The equilibrium value of collateral can be specified in the model, thus allowing the analysis of its impact on default, asset prices and welfare.

The importance of asymmetric or incomplete information and of co-ordination failures for financial fragility is well known (eg Morris and Shin (2000)). So long as appropriate information partitions are introduced, then these issues can be studied in the context of this model. The viability of the rational expectations hypothesis in conjunction with informational content of prices can be addressed, and the impact of asymmetries of information can be studied empirically.

And finally, turning to a major current issue: the long-run effects of the proposed New Basel Accord can be appraised by extending the model to an infinite horizon. 


\section{References}

Allen, F and Gale, D (1998), 'Optimal financial crises', Journal of Finance, Vol. 53, pages $1,245-84$.

Allen, F and Gale, D (2000), 'Bubbles and crashes', Economic Journal, Vol. 460, pages 236-55.

Arrow, K J (1953), 'Generalisation des Theories de l'Equilibre Economique General et du Rendement Social au cas du Risque', Econometrie Paris, CNRS, pages 81-120.

Bank for International Settlements (1998), 'Implications of structural change for the nature of systemic risk', Basel, Switzerland.

Basel Committee on Banking Supervision (2001), 'The New Basel Accord', Bank for International Settlements, Basel, Switzerland.

Bernanke, B S, Gertler, M and Gilchrist, S (1999), 'The financial accelerator in a quantitative business cycle framework', in Taylor, J B and Woodford, M (eds), Handbook of macroeconomics, Vol. 1, North-Holland.

Blum, J and Hellwig, M (1995), 'The macroeconomic consequences of capital adequacy requirements for banks', European Economic Review, Vol. 39, pages 739-49.

Bryant, J (1982), 'A model of reserves, bank runs, and deposit insurance', Journal of Banking and Finance, Vol. 4, pages 335-44.

Buiter, W H (1998), 'Neutrality, price level indeterminacy, interest rate pegs, and fiscal theories of the price level', NBER Working Paper, No. 6396, February.

Buiter, W H (1999), 'The fallacy of the fiscal theory of the price level', Center for Economic Research Discussion Paper, Vol. 2,205.

Catarineu-Rabell, E, Jackson, P and Tsomocos, D P (2001), 'Procyclicality and the new Basel Accord - banks' choice of loan rating system', mimeo, Bank of England.

Clower, B W (1965), 'The Keynesian counterrevolution: a theoretical appraisal', in Hahn, F H and Brechling, F P R (eds), The theory of interest rates, Macmillan.

Clower, B W (1967), 'A reconsideration of the microeconomic foundations of monetary theory', Western Economic Journal, Vol. 6, pages 1-8.

Crockett, A (1997), 'Maintaining financial stability in a global economy', in Federal Reserve Bank of Kansas City's Symposium, Jackson Hole, Wyoming, 28-30 August.

Debreu, G (1951), 'The coefficient of resource utilization', Econometrica, Vol. 19, pages $273-92$. 
Diamond, D and Dybvig, P (1983), 'Bank runs, deposit insurance and liquidity', Journal of Political Economy, Vol. 91, pages 401-19.

Dubey, P and Geanakoplos, J (1992), 'The value of money in a finite-horizon economy: a role for banks', in Dasgupta, P and Gale, D et al (eds), Economic analysis of market and games, Cambridge: MIT press.

Dubey, P and Geanakoplos, J (1993), 'Monetary equilibrium with incomplete markets', forthcoming CFDP.

Dubey, P, Geanakoplos, J and Shubik, M (2000), 'Default in a general equilibrium model with incomplete markets', Cowles Foundation DP 1247, Yale University.

Dubey, $P$ and Shubik, M (1978), 'The non-cooperative equilibria of a closed trading economy with market supply and bidding strategies', Journal of Economics Theory, Vol. 17, pages 1-20.

Freixas, X and Rochet, J-C (1998), Microeconomics of banking, Cambridge, Massachusetts: The MIT Press.

Geanakoplos, J D and Polemarchakis, H M (1986), 'Existence, regularity and constrained suboptimality of competitive allocations when the asset market is incomplete', in Heller, W and Starret, D (eds), Essays in honor of K. Arrow, Vol. III, Cambridge, UK: Cambridge University Press.

Geanakoplos, J D and Tsomocos, D P (2002), 'International finance in general equilibrium', Ricerche Economiche, Vol. 1/2002.

Gonzalez-Hermosillo, B (1999), 'Determinants of ex-ante banking system distress: a macro-micro empirical exploration of some recent episodes', IMF Working Paper, Washington DC.

Grandmont, J M (1983), Money and value, Cambridge: Cambridge University Press.

Grandmont, J M and Laroque, G (1973), 'On money and banking', Review of Economic Studies, pages 207-36.

Grandmont, J M and Younes, Y (1972), 'On the role of money and the existence of a monetary equilibrium', Review of Economic Studies, Vol. 39, pages 355-72.

Grandmont, J M and Younes, Y (1973), 'On the efficiency of a monetary equilibrium', Review of Economic Studies, pages 149-65.

Gurley, J G, and Shaw, E S (1960), Money in a theory of finance, Washington, DC: Brookings.

Hahn, F H (1965), 'On some problems of proving the existence of an equilibrium in a monetary economy', in Hahn, F H and Brechling, F R P (eds), The theory of interest rates, Macmillan.

Hart, O (1975), 'On the optimality of equilibrium when the market structure is incomplete', Journal of Economic Theory, Vol. 11, pages 418-43. 
Hicks, J R (1946), Value and capital, 2nd Edition, Oxford: Oxford University Press.

Hool, R B (1976), 'Money, expectations and the existence of a temporary equilibrium', Review of Economic Studies, Vol. 40, pages 439-45.

International Monetary Fund (1998), 'Chapter IV: Financial crises: characteristics and vulnerability', World Economic Outlook, Washington DC.

Lucas, R E (1980), 'Equilibrium in a pure currency economy', in Kareken, J H and Wallace, N (eds), Models of monetary economies, Minneapolis: Federal Reserve Bank of Minneapolis.

Lucas, R E (1990), 'Liquidity and interest rates', Journal of Economic Theory, Vol. 50, pages $237-64$.

Lucas, R E and Stokey, N (1987), 'Money and interest in a cash in advance economy', Econometrica, SS: pages 491-514.

Mishkin, F S (1994), 'Global financial instability: framework, events, issues', Journal of Economic Perspectives, Vol. 13(4), Fall, pages 3-25.

Morris, S and Shin, H Y (2000), 'Rethinking multiple equilibria in macroeconomic modelling', Cowles Foundation DP 1260, Yale University.

Radner, R (1972), 'Existence of equilibrium plans, prices, and price expectations in a sequence of markets', Econometrica, Vol. 40(2), pages 289-303.

Shapley, L S and Shubik, M (1977), 'Trading using one commodity as a means of payment', Journal of Political Economy, Vol. 85(5), pages 937-68.

Shubik, M (1973), 'Commodity money, oligopoly, credit and bankruptcy in a general equilibrium model', Western Economic Journal, Vol. 11, pages 24-38.

Shubik, M (1999), The theory of money and financial institutions, Cambridge, Massachusetts: The MIT Press.

Shubik, M and Tsomocos, D P (1992), 'A strategic market game with a mutual bank with fractional reserves and redemption in gold', Journal of Economics, Vol. 55(2), pages 123-50.

Shubik, M and Wilson, C (1977), 'The optimal bankruptcy rule in a trading economy using fiat money', Journal of Economics, Vol. 37, pages 337-54.

Tobin, J (1963), 'Commercial banks as creators of 'money', in Carson, D (ed), Banking and monetary studies, for the Comptroller of the Currency, US Treasury, Richard D. Irwin, Inc., Homewood, Illinois, 1963.

Tobin, J (1982), 'The commercial banking firm: a simple model', Scandinavian Journal of Economics, Vol. 84(4), pages 495-530.

Tsomocos, D P (2000), 'Equilibrium analysis, banking and financial instability', mimeo, Bank of England. 
Tsomocos, D P (2001), 'Monetary and regulatory policy non-neutrality, constrained inefficiency and determinacy', mimeo, Bank of England.

Tsomocos, D P (2002), 'The microfoundations of default in general equilibrium', mimeo, Bank of England. 


\section{Appendix I}

\section{I.1 NBPS}

The macrovariables which are determined in equilibrium, and which every agent regards as fixed, are denoted by $\eta=\left(p, \rho, r_{s}, \bar{r}, \theta, R\right)$. The choices of the NBPS $h \in H$, are denoted by $\sigma^{h} \in \Sigma^{h}(\eta)$

where,

$\sigma^{h}=\left(\chi^{h}, \bar{\mu}^{h}, \mu^{h}, d^{h}, \bar{d}^{h}, b^{h}, q^{h}, u^{h}, v^{h}\right) \in R_{+}^{L S^{*}} \times R_{+} \times R_{+}^{S^{*}} \times R_{+}^{S^{*}} \times R_{+} \times R_{+}^{L S^{*}+J} \times R_{+}^{L S^{*}+J} \times R_{+}^{B} \times R_{+}^{S^{*}+J+1}$

is the vector of all of NBPS's decisions.

The variables represent the following quantities:

$\chi^{h} \equiv$ consumption,

$\bar{\mu}^{h} \equiv$ long-term loan,

$\mu_{s}^{h} \equiv$ short-term loans at each $s \in S^{*}$,

$\bar{d}^{h} \equiv$ long-term deposits,

$d_{s}^{h} \equiv$ short-term deposits,

$b_{s l}^{h},\left(b_{j}^{h}\right) \equiv$ amounts of money offered in the goods (asset) markets,

$q_{s l}^{h},\left(q_{j}^{h}\right) \equiv$ sales of goods and assets,

$u^{h} \equiv$ bid for ownership shares of the commercial banks, and

$v_{n(j)}^{h},\left(\bar{v}_{s}^{h}\right) \equiv$ percentage deliveries of promised short-term loans, marketed assets and long-term loans.

$$
\text { ( ) }\{\Sigma \in(-\neq:(1)-(10) \text { below }\}
$$


$x_{0 l}^{h} \leq e_{0 l}^{h}-q_{0 l}^{h}+\frac{b_{0 l}^{h}}{p_{0 l}}, \forall l \in L$

$\forall s \in S$

$d_{s}^{h} \leq \Delta\left(4^{h}\right)+m_{s}^{h}$

$\sum_{l \in L} b_{s l}^{h}+\sum_{j \in J}\left(v_{s j}^{h} p_{s} A_{s}^{j}\right) q_{j}^{h}+\bar{v}_{s}^{h} \bar{\mu}^{h} \leq \Delta\left(6^{h}\right)+\frac{\mu_{s}^{h}}{\left(1+r_{s}\right)}+\overline{R_{d s}} \bar{d}^{h}(1+\bar{r})$

$q_{s l}^{h} \leq e_{s l}^{h} \quad, \quad \forall l \in L$

$v_{s}^{h} \mu_{s}^{h} \leq \Delta\left(7^{h}\right)+\sum_{j \in J}\left(R_{s j} p_{s} A_{s}^{j}\left(\frac{b_{j}^{h}}{\theta_{j}}\right)+R_{d s} d_{s}^{h}\left(1+r_{s}\right)+\sum_{b \in B}\left(\frac{u^{h}}{\sum_{h \in H} u^{h}}\right) \pi_{s}^{b}+\sum_{l \in L} p_{s l} q_{s l}^{h}\right.$

$x_{s l}^{h} \leq e_{s l}^{h}-q_{s l}^{h}+\frac{b_{s l}^{h}}{p_{s l}} \quad, \quad \forall l \in L$

\section{I.2 Commercial banks}

Denote the choices of a commercial bank $b \in B, \sigma^{b} \in \Sigma^{b}(\eta)$, where

$\sigma^{b}=\left(\mu^{b}, d^{b}, \bar{m}^{b}, m_{s}^{b}, b_{j}^{b}, q_{j}^{b}, c_{s}^{b}, v_{s}^{b}, \pi_{s}^{b}\right) \in R_{+} \times R_{+} \times R_{+} \times R_{+}^{S^{*}} \times R_{+}^{J} \times R_{+}^{J} \times R_{+}^{S^{*}} \times R_{+}^{S^{*}+J+2} \times R_{+}^{S^{*}}$ is the vector of all its market decisions.

The variables represent the following quantities:

$\mu^{b} \equiv$ interbank market loans,

$d^{b} \equiv$ interbank market lending (deposits),

$m_{s}^{b} \equiv$ credit extension at the various short-term credit markets,

$m^{b} \equiv$ credit extension at the long-term credit market,

$b_{j}^{b} \equiv$ amount of money offered for the purchase of marketed assets,

$q_{j}^{b} \equiv$ sales of assets,

$c_{s}^{b} \equiv$ capital adjustment,

$v_{s(j)}^{b},\left(\bar{v}_{s}^{b}, v_{s}, \widetilde{v}_{s}^{b}\right) \equiv$ percentage deliveries of promised assets, interest rate payments on deposits and interbank loans

$\pi_{s}^{b} \equiv$ final monetary holdings (profits) in every state. 
$B^{b}(\eta)=\left\{\sigma^{b} \in \Sigma^{b}(\eta):(1)-(7)\right.$ below $\}$ is the budget set, where $\Delta(\mathrm{i})$ represents the difference between RHS and LHS of inequality (i).

For $t=0$,

$d^{b} \leq e_{0}^{b}$

$m_{0}^{b}+\stackrel{-b}{m}^{b} \sum_{j \in J} b_{j}^{b} \leq\left(\Delta\left(1^{b}\right)+\frac{\mu^{b}}{(1+\rho)}+\sum_{h \in H} u_{b}^{h}\right)$

$\left(v_{0}\left(1+r_{0}\right) \sum_{h \in H} d_{0}^{h}\right) z_{0}+c_{0}^{b} \leq \Delta\left(2^{b}\right)+\left(R_{0} \sum_{h \in H} \mu_{0}^{h}\right) z_{0}+\sum_{j \in J} \theta_{j} q_{j}^{b}$

$k_{b 0} \leq \frac{e_{0}^{b}+\sum_{h \in H} u_{b}^{h}+c_{0}^{b}}{w_{00}^{b}(\eta, \sigma) R_{0} m_{0}^{b}\left(1+r_{0}\right)+w_{00}^{b}(\eta, \sigma) \bar{m}^{b}(1+\bar{r})+\sum_{j \in J} w_{0 j}^{b}(\eta, \sigma)\left(p_{s} A_{s}^{j}\right)\left(\frac{b_{j}^{b}}{\theta_{j}}\right)+w_{00^{*}}^{b}(\eta, \sigma)(1+\rho) d^{b}}$

$\forall s \in S$,

$m_{s}^{b}+\left(\sum_{h \in H} \bar{v}_{s}^{b}(1+\bar{r}) \bar{d}^{h}\right) \bar{z} \leq \Delta\left(3^{b}\right)+\left(\sum_{h \in H} \bar{R}_{s} \bar{\mu}^{h}\right) \bar{z}+e_{s}^{b}=\pi_{0}^{b}$

$\Delta\left(5^{b}\right)+\sum_{j \in J}\left(R_{j} p_{s} A_{s}^{j}\right)\left(\frac{b_{j}^{b}}{\theta_{j}}\right)+\widetilde{R}_{\mathrm{ds}} d^{b}(1+\rho) z+\left(\sum_{h \in H} R_{s} \mu_{s}^{h}\right) z_{s}$

$k_{b s} \leq \frac{e_{s}^{b}+\sum_{h \in H} u_{b}^{h}+c_{s}^{b}}{w_{s s}^{b}(\eta, \sigma) R_{s} m_{s}^{b}\left(1+r_{s}\right)+w_{s 0}^{b}(\eta, \sigma) \bar{R}_{s} \bar{m}^{b}(1+\bar{r})+\sum_{j \in J} w_{s j}^{b}(\eta, \sigma) R_{s j}\left(p_{s} A_{s}^{j}\right)\left(\frac{b_{j}^{b}}{\theta_{j}}\right)+w_{s 0^{b}}{ }^{b} \widetilde{R}_{d s}(1+\rho) d^{b}}$

where, $z_{s}=m_{s}^{b} /\left(\sum_{h \in H} d^{h}+\sum_{b \in B} m_{s}^{b}\right), \bar{z}=\bar{m}^{b} /\left(\sum_{h \in H} \bar{d}^{h}+\sum_{b \in B} \bar{m}^{b}\right), z=d^{b} /\left(\sum_{b \in B} d^{b}+M^{G}\right)$, and $\pi_{s}^{b}=\Delta\left(6^{b}\right)$ 


\section{Appendix II}

\section{Proof of Theorem 1:}

Let $M^{*} \equiv M^{G}+\sum_{\mathrm{h} \in \mathrm{H}} \sum_{\mathrm{s} \in \mathrm{S}^{*}} \mathrm{~m}_{\mathrm{s}}^{\mathrm{h}}+\sum_{\mathrm{b} \in \mathrm{B}} \sum_{\mathrm{s} \in \mathrm{S}^{*}} \mathrm{e}_{\mathrm{s}}^{\mathrm{b}}$ be the total quantity of money ever appearing in the economy. For $h \in H, b \in B$ and $\varepsilon>0$ let

$\sum_{\varepsilon}^{\mathrm{h}}=\left\{\left(x^{h}, \bar{\mu}^{h}, \mu^{h}, d^{h}, \bar{d}^{h}, b^{h}, q^{h}, u^{h}, v^{h}\right) \in \mathfrak{R}_{+}^{L S^{*}} \times \mathfrak{R}_{+} \times \mathfrak{R}_{+}^{S^{*}} \times \mathfrak{R}_{+}^{S^{*}} \times \mathfrak{R}_{+} \times \mathfrak{R}_{+}^{L S^{*}+J} \times \mathfrak{R}_{+}^{L S^{*}+J} \times \mathfrak{R}_{+}^{B} \times \mathfrak{R}_{+}^{S^{*}+J+1}:\right.$

$0 \leq \mathrm{x}^{\mathrm{h}} \leq 2 \mathrm{~A} 1, \varepsilon \mathrm{m}_{\mathrm{s}}^{\mathrm{h}} \leq \mu_{\mathrm{s}}^{\mathrm{h}} \leq \frac{1}{\varepsilon}, \varepsilon \mathrm{m}_{0}^{\mathrm{h}} \leq \bar{\mu}_{\mathrm{s}}^{\mathrm{h}} \leq \frac{1}{\varepsilon}, 0 \leq \mathrm{d}_{\mathrm{s}}^{\mathrm{h}} \leq \mathrm{M}^{*}, 0 \leq \overline{\mathrm{d}}^{\mathrm{h}} \leq \mathrm{M}^{*}$,

$\left.\varepsilon \mathrm{m}_{\mathrm{s}}^{\mathrm{h}} \leq \mathrm{b}_{\mathrm{sl}}^{\mathrm{h}}\left(\mathrm{b}_{\mathrm{j}}^{\mathrm{h}}\right) \leq \frac{1}{\varepsilon}, \varepsilon \leq \mathrm{q}_{\mathrm{sl}}^{\mathrm{h}}\left(\mathrm{q}_{\mathrm{j}}^{\mathrm{h}}\right) \leq \frac{1}{\varepsilon}, \varepsilon \mathrm{m}_{0}^{\mathrm{h}} \leq \mathrm{u}^{\mathrm{h}} \leq \frac{1}{\varepsilon}, \varepsilon \leq \mathrm{v}^{\mathrm{h}} \leq 1\right\}$

and

$\sum_{\varepsilon}^{\mathrm{b}}=\left\{\left(\mu^{b}, d^{b}, \bar{m}^{b}, m_{s}^{b}, b_{j}^{b}, q_{j}^{b}, c_{s}^{b}, v_{s}^{b}, \pi_{s}^{b}\right) \in \mathfrak{R}_{+} \times \mathfrak{R}_{+} \times \mathfrak{R}_{+} \times \mathfrak{R}_{+}^{S^{*}} \times \mathfrak{R}_{+}^{J} \times \mathfrak{R}_{+}^{J} \times \mathfrak{R}_{+}^{s^{*}+j+2} \times \mathfrak{R}_{+}^{s^{*}}:\right.$

$\varepsilon \mathrm{e}_{0}^{\mathrm{b}} \leq \mu^{\mathrm{b}} \leq \frac{1}{\varepsilon}, 0 \leq \mathrm{d}^{\mathrm{b}} \leq \mathrm{M}^{*}, \varepsilon \mathrm{e}_{0}^{\mathrm{b}} \leq \overline{\mathrm{m}}^{\mathrm{b}} \leq \frac{1}{\varepsilon}, \varepsilon \mathrm{e}_{\mathrm{s}}^{\mathrm{b}} \leq \mathrm{m}_{\mathrm{s}}^{\mathrm{b}} \leq \frac{1}{\varepsilon}, \varepsilon \mathrm{e}_{0}^{\mathrm{b}} \leq \mathrm{b}_{\mathrm{j}}^{\mathrm{b}} \leq \frac{1}{\varepsilon}, \varepsilon \leq \mathrm{q}_{\mathrm{j}}^{\mathrm{b}} \leq \frac{1}{\varepsilon}$,

$\left.\varepsilon \leq \mathrm{c}_{\mathrm{s}}^{\mathrm{b}} \leq \mathrm{M}^{*}, \varepsilon \leq \mathrm{v}_{\mathrm{s}}^{\mathrm{b}} \leq 1, \varepsilon \mathrm{e}_{\mathrm{s}}^{\mathrm{b}} \leq \pi_{\mathrm{s}}^{\mathrm{b}} \leq \mathrm{M}^{*}\right\}$

which are both compact and convex.

Let the typical element of $\sum_{\varepsilon}^{\mathrm{h}}\left(\sum_{\varepsilon}^{\mathrm{b}}\right)$ be $\sigma^{h}\left(\sigma^{b}\right) \in \sum_{\varepsilon}^{\mathrm{h}}\left(\sum_{\varepsilon}^{\mathrm{b}}\right)$. Define

$\mathrm{B}_{\varepsilon}^{\mathrm{h}}(\eta)=\mathrm{B}^{\mathrm{h}}(\eta) \cap \sum_{\varepsilon}^{\mathrm{h}}$ and $\mathrm{B}_{\varepsilon}^{\mathrm{b}}(\eta)=\mathrm{B}^{\mathrm{b}}(\eta) \cap \sum_{\varepsilon}^{\mathrm{h}}$. Also let

$\sigma=\left(\sigma^{l}, \ldots, \sigma^{H}, \ldots, \sigma^{B+H}\right) \in \sum_{\varepsilon}=X_{h \in H \cup B} \sum_{\varepsilon}^{\mathrm{h}}$. Define the map

$\Psi_{\varepsilon}: \sum_{\varepsilon} \rightarrow N$, where

$\mathrm{N}=\left\{\eta=\left(\mathrm{p}, \rho, \mathrm{r}_{\mathrm{s}}, \overline{\mathrm{r}}, \theta, \mathrm{R}\right) \in\left(\mathfrak{R}_{++}^{L S^{*}} \times \mathfrak{R}_{++} \times \mathfrak{R}_{++}^{s^{*}} \times \mathfrak{R}_{++} \times \mathfrak{R}_{++}^{J} \times \mathfrak{R}_{+}^{S^{*}+1+J}\right\}\right.$

and $\Psi_{\varepsilon}$ is defined by equation (i)-(ix). In addition define $(\eta, \sigma)$ to be an $\varepsilon-M E C B D$ if $\eta=\Psi_{\varepsilon}(\sigma)$ and (x), (ie (a) $\sigma^{\mathrm{h}} \in \underset{\sigma^{\mathrm{h}} \in \mathrm{B}_{\varepsilon}^{\mathrm{h}}(\eta)}{\operatorname{Arg} \max } \Pi^{\mathrm{h}}\left(x^{h}\left(\sigma^{h}\right)\right)$ and (b) $\left.\sigma^{\mathrm{b}} \in \underset{\sigma^{\mathrm{b}} \in \mathrm{B}_{\varepsilon}^{\mathrm{b}}(\eta)}{\operatorname{Arg} \max } \Pi^{\mathrm{b}}\left(x^{b}\left(\sigma^{b}\right)\right)\right)$. Note also that all

elements of $\Psi_{\varepsilon}(\sigma)=\eta$ are continuous functions of $\sigma$, since in each market some agents are bidding (offering) strictly positive amounts and repayments are bounded away from 0 by the inactive market hypothesis.

Furthermore, define

$G: N \rightrightarrows \underset{\mathrm{h} \in \mathrm{H} \cup \mathrm{B}}{\mathrm{X}} \sum_{\varepsilon}^{\mathrm{h}}=\sum_{\varepsilon}$, where

$G^{h}=\sigma^{\mathrm{h}} \in \underset{\sigma^{\mathrm{h}} \in \mathrm{B}_{\mathrm{\varepsilon}}^{\mathrm{h}}(\eta)}{\operatorname{Arg} \max } \Pi^{\mathrm{h}}\left(x^{h}\left(\sigma^{h}\right)\right)$ and $G=\underset{\mathrm{h} \in \mathrm{H}}{\mathrm{X}} \mathrm{G}^{\mathrm{h}}$.

Finally, let $F=G \circ \Psi: \sum_{\varepsilon} \rightrightarrows \sum_{\varepsilon} G$ is convex-valued since $\sigma \rightarrow u^{h}\left(x^{h}\left(\sigma^{h}\right)\right)$ is concave. Recall, $\sigma^{h} \rightarrow x^{h}\left(\sigma^{h}\right)$ is linear, and that $\mathrm{B}_{\varepsilon}^{\mathrm{h}}(\eta)$ is convex. Since $\Psi$ is a function, $F=G \circ \Psi$ is also convex valued. Moreover, if $\varepsilon$ is sufficiently small, $G$ is non-empty, since $m_{s}^{h}, e_{s}^{b}>0 \forall h \in H, b \in B$. When $\varepsilon>0, p_{s l}, \theta, r_{s}, r, R>0$, and since $e^{h}, e^{b} \neq 0, \mathrm{~B}_{\varepsilon}^{\mathrm{h}}(\eta)$ for $h \in H \cup B$ is a continuous 
correspondence. Hence, by the maximum theorem, $G$ is compact-valued and upper semicontinuous, and therefore so is $F$. Note that since we have restricted the domain of $\Psi$ to $\sum_{\varepsilon}$ and since for each good and money, some $h \in H \cup B$ has a strictly positive endowment, the restriction $\Psi$ to strictly positive prices, and interest rates strictly greater than -1 is legitimate. The same applies for $R$ 's since an external agent always guarantees a minimum repayment $\varepsilon>0$ by the inactive markets hypothesis. Finally, observe that the total amount of money is bounded above. Commodity prices, $p_{s l} \leq\left(M^{*}+\varepsilon / L \cdot S^{*} /\right) / \varepsilon \leq 2 M^{*} / \varepsilon \forall s l$. Thus, $p_{s l} A_{j}$ is bounded above and so the external agent never delivers more $\frac{\left|\mathrm{L} \cdot \mathrm{S}^{*}\right| \varepsilon^{2} 2 \mathrm{M}^{*}}{2 \mathrm{M}^{*} \cdot \varepsilon} \leq \varepsilon$ units of money. Thus the total amount of money is $M^{*}+\left(/ L \cdot S^{*} /+/ J /\right) \varepsilon \leq 2 M^{*}$.

Step 1: An $\varepsilon-M E C B D$ exists for any sufficiently small $\varepsilon>0$.

Proof: The map $F$ satisfies all the conditions of the Kakutani fixed point theorem, and therefore admits a fixed point $F(\sigma) \ni \sigma$ which satisfies (i)-(xiii) for an $\varepsilon$-MECBD.

For every small $\varepsilon>0$, let $\left(\eta(\varepsilon), \sigma_{\varepsilon}\right)$ denote the corresponding $\varepsilon-M E C B D$.

Step 2: At any $\varepsilon-M E C B D, r_{s}(\varepsilon), \overline{\mathrm{r}}(\varepsilon), p(\varepsilon) \geq 0 \quad \forall s \in S^{*}$.

Proof: By Propositions III.1.1 and 2.

Step 3: At any $\varepsilon-M E C B D \exists I, Z<\infty \ni r_{s}(\varepsilon), \overline{\mathrm{r}}(\varepsilon), \rho(\varepsilon)<I$ and $\bar{\mu}^{\mathrm{h}}(\varepsilon), \mu_{\mathrm{s}}^{\mathrm{h}}(\varepsilon), \mu^{\mathrm{b}}(\varepsilon) \leq Z, \forall s \in S^{*}$, $h \in H, b \in B$.

Proof: Suppose that $r_{s}(\varepsilon) \rightarrow \infty$. Then $\exists h \in H$ such that $\mu_{\mathrm{s}}^{\mathrm{h}}(\varepsilon) \rightarrow \infty$ and consequently $\mathrm{D}_{\mathrm{sN}(\mathrm{s})}^{\mathrm{h}}=\left(\mu_{\mathrm{s}}^{\mathrm{h}}-\mathrm{M}^{*}\right) \rightarrow \infty$. Then, since $\lambda>>0, \frac{\nabla \pi_{\mathrm{sl}}^{\mathrm{h}}}{\mathrm{p}_{\mathrm{sl}}(\varepsilon)}<<\lambda \mathrm{D}_{\mathrm{sN}(\mathrm{s})}^{\mathrm{h}}$. Thus, $h$ could have been better off by reducing $\mu_{\mathrm{s}}^{\mathrm{h}}(\varepsilon)$ by $\Delta$, a contradiction. Similarly, for $\overline{\mathrm{r}}(\varepsilon), \rho(\varepsilon), \mu_{\mathrm{s}}^{\mathrm{h}}(\varepsilon), \mu^{\mathrm{b}}(\varepsilon)$.

Step 4: For any $\varepsilon-M E C B D, \exists c>0 \ni p_{s l}(\varepsilon)>c, \forall s \in S^{*}, l \in L$.

Proof: Suppose that $p_{s l}(\varepsilon) \rightarrow 0$ for some $s \in S^{*}, l \in L$. Then choose $h \in H$. He could have borrowed $\Delta$ more to buy $\Delta p_{s l}(\varepsilon) \rightarrow \infty$. His net gain in utility would be $\left(\frac{\nabla \pi_{\mathrm{sl}}^{\mathrm{h}}}{\mathrm{p}_{\mathrm{sl}}}-\lambda_{\mathrm{sl}}^{\mathrm{h}} \mathrm{r}_{\mathrm{s}}\right) \Delta>0$ since $\lambda_{\mathrm{sl}}^{\mathrm{h}} \mathrm{r}_{\mathrm{s}}<\infty$ and by $(\mathrm{A} 3), \pi^{h}(0, \ldots, Q, \ldots, 0)>u^{h}(A 1)$ with $Q$ in the $s l$ th place. Thus, $p_{s l} \geq$ $\nabla \Pi_{s l}^{h} / \lambda_{s l}^{h} r_{s}>c>0$.

Step 5: For any $\varepsilon-M E C B D \exists \Gamma \ni \mathrm{q}_{\mathrm{j}}^{\mathrm{h}}(\varepsilon)<\Gamma, \forall j \in J, h \in H \cup B$.

Proof: Suppose that for some $j \in J, \mathrm{q}_{\mathrm{j}}^{\mathrm{h}}(\varepsilon) \rightarrow \infty$ and $\mathrm{A}_{\mathrm{sl}}^{\mathrm{j}}>0$, for some $l \in L$. Then $h$ can deliver at most $\mathrm{q}_{\mathrm{j}}^{\mathrm{h}} \mathrm{A}_{\mathrm{sl}}^{\mathrm{j}} \leq \max _{\substack{1 \leq 1 \leq \mathrm{L} \\ \mathrm{s} \in \mathrm{S}^{*}}} \sum_{\mathrm{h} \in \mathrm{H}} \mathrm{e}_{\mathrm{sl}}^{\mathrm{h}}=\overline{\mathrm{e}}$, and therefore his disutility from default would be $\left(\lambda_{\mathrm{j}}^{\mathrm{h}} \mathrm{p}_{\mathrm{sl}} \mathrm{q}_{\mathrm{j}}^{\mathrm{h}} \mathrm{A}_{\mathrm{sl}}^{\mathrm{j}}-\mathrm{M}^{*}\right) / p_{s} g_{s}$

$<u(A 1)$. Otherwise, $\sigma^{h}(\varepsilon)$ are not optimal.

Similarly, suppose that $A_{s, m}^{j}>0$. Again $h$ can deliver at most $q_{j}^{h} A_{S, m} \leq \overline{\mathrm{e}}$ and then his disutility from default would be $\left(q_{j}^{h} A_{S, m}\right) / p_{s} g_{s} \leq u(A 1)$. Otherwise, he would not have optimised.

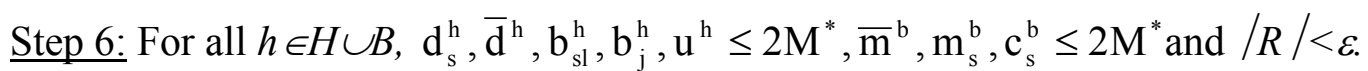


Proof: All variables are constrained by the total amount of money present in the economy and $R$ by assumption.

Step 7: For all $h \in H \cup B, \sigma_{\varepsilon}^{\mathrm{h}}=\underset{\sigma_{\varepsilon}^{\mathrm{h}} \in \mathrm{B}^{\mathrm{h}}(\eta(\varepsilon))}{\arg \max } \pi^{\mathrm{h}}\left(\mathrm{x}^{\mathrm{h}}\left(\sigma^{\mathrm{h}}\right)\right)$, for sufficiently small $\varepsilon>0$.

Proof: From steps 2-6 and the budget constraints $\left(3^{h}\right),\left(8^{h}\right)$ of I.1 and $\left(1^{h}\right)$ of I.2, the $\varepsilon$-constraint is not binding thus concavity of payoffs guarantees the optimality of $\sigma^{h}(\varepsilon)$.

$\operatorname{MECBD}(\eta, \sigma)$ will be constructed by taking the limit of $\varepsilon-\operatorname{MECBD}(\eta(\varepsilon), \sigma(\varepsilon))$, as $\varepsilon \rightarrow 0$. This is achieved by taking limits of sequences of $\varepsilon$ and subsequences of subsequences.

Step 8: If for some $\bar{s} \bar{l}, p_{\bar{s} \bar{l}}(\varepsilon) \rightarrow \infty$, then $p_{s l}(\varepsilon) \rightarrow \infty \forall s \in S, l \in L$. Also, if either $\theta_{j}(\varepsilon) \rightarrow \infty$, or $p_{\text {ol }}(\varepsilon) \rightarrow \infty$ then $p_{s l} \rightarrow \infty, \forall l \in L, s \in S^{*}$.

Proof: Some $h$ owns $e_{\bar{s} \bar{l}}^{h}>0$. If $p_{s l}(\varepsilon)$ stays bounded on some subsequence, then by borrowing very large $\bar{\mu}^{\mathrm{h}}$ or $\mu_{0}^{\mathrm{h}}$ if $s=0, h$ can use it to buy $Q$ units of $s l$. Then since $\overline{\mathrm{r}}(\varepsilon), r_{s}(\varepsilon)<I, h$ can sell $\Delta$ of $\overline{\mathrm{s}} \overline{\mathrm{l}}$ acquire $\Delta \mathrm{p}_{\bar{s} \bar{l}}(\varepsilon) \rightarrow \infty$ to defray his loan and improve his utility, a contradiction.

If $\theta_{j}(\varepsilon) \rightarrow \infty$ for some $j \in J$ and $p_{s l}(\varepsilon)<\infty$, let h borrow $\Delta \theta_{j}(\varepsilon) /\left(1+r_{0}(\varepsilon)\right)$ and buy $\Delta q_{j}(\varepsilon) /\left(1+r_{0}(\varepsilon)\right)$ $p_{s l}(\varepsilon)$ of $s l$ and improve his utility. If $\mathrm{p}_{0 \overline{1}}(\varepsilon) \rightarrow \infty$, as previously argued then $p_{o l}(\varepsilon) \rightarrow \infty, \forall l \in L$.

Then, by selling $\Delta$ of ol $h$ can acquire $\Delta p_{0 l}(\varepsilon) \rightarrow \infty$. If any of $p_{s l}(\varepsilon) \rightarrow \infty, \forall \mathrm{s} \in \mathrm{S}$ then by inventorying money he can improve upon his utility.

Step 9: $\exists K>0 \ni p_{s l}(\varepsilon) / p_{s k}(\varepsilon)<k, \forall l, k \in L, s \in S$.

Proof: Suppose the opposite. Then take $h$ with $\mathrm{e}_{\mathrm{sl}}^{\mathrm{h}}>0$. Let him reduce $\Delta$ his sales of $s l$ and lose $\Delta\left(\Pi^{h}(A 1)-\Pi^{h}(0)\right)$ at most. Then he could buy more $s k$ buy borrowing $\Delta p_{s l}(\varepsilon) /\left(1+r_{s}(\varepsilon)\right)$ and sell $\Delta$ of $s l$. His net gain in utility would be

$\Delta(\varepsilon)\left\{\frac{\mathrm{p}_{\mathrm{sl}}(\varepsilon)}{\left(1+\mathrm{r}_{\mathrm{s}}(\varepsilon) \mathrm{p}_{\mathrm{sk}}(\varepsilon)\right.}\left(\nabla \Pi_{\mathrm{sk}}^{\mathrm{h}}\left(\mathrm{x}^{\mathrm{h}}\right)\right)-(\Pi(\mathrm{A} 1)-\Pi(0)\}>0\right.$

since $p_{s l}(\varepsilon) / p_{s k}(\varepsilon) \rightarrow \infty$ and by step $3, r_{s}(\varepsilon)<I$.

Step 10: $\exists \mathrm{K}^{\prime}>0 \ni p_{\text {ol }}(\varepsilon) / p_{s l}(\varepsilon)<\mathrm{K}^{\prime}, \forall s \in S^{*}, l \in L$.

Proof: If $s=0$ then step 9 obtains. Otherwise, set $\Delta\left(4^{h}\right)$ of I.1 equal to $\Delta p_{s l}(\varepsilon) / 1+r_{s}(\varepsilon)$.

$\underline{\text { Step 11: }} \theta_{\mathrm{j}}(\varepsilon) / \sum \mathrm{p}_{\mathrm{ol}}(\varepsilon) \nrightarrow \infty, \forall j \in J$

Proof: Suppose the contrary. Let $h$ sell $\frac{\Delta}{(1+\overline{\mathrm{r}}(\varepsilon))}$ of $j$ and borrow $\frac{\Delta \cdot \theta_{\mathrm{j}}(\varepsilon)}{(1+\overline{\mathrm{r}}(\varepsilon))}$ more.

Let him consume $\frac{\Delta \cdot \theta_{j}}{(1+\bar{r}(\varepsilon)) p_{o l}(\varepsilon)}$ more $o l$ for some $l \in L$ in $s=0$.

Then $h$ can use the proceeds of the asset sale to defray the loan. His net gain of this action will be $\Delta\left(\frac{\theta_{\mathrm{j}}}{\left(1+\overline{\mathrm{r}}(\varepsilon) \mathrm{p}_{\mathrm{ol}}\right.}-\frac{\mathrm{A}_{\mathrm{sl}}^{\mathrm{j}}}{(1+\overline{\mathrm{r}}(\varepsilon)}\right)>0$ 
since $\frac{\theta_{\mathrm{j}}(\varepsilon)}{\mathrm{p}_{01}(\varepsilon)} \rightarrow \infty$

Step 12: If $\theta_{j}(\varepsilon) / \sum_{l \in L} p_{0 l}(\varepsilon) \rightarrow 0$ then $\mathrm{A}_{\mathrm{sl}}^{\mathrm{j}}=0, \forall l \in L$ and $\sum_{l \in \mathrm{L}} \mathrm{p}_{01}(\varepsilon) \rightarrow \infty$, whenever $\mathrm{A}_{\mathrm{sm}}^{\mathrm{j}}>0$, $\forall s \in S$.

Proof: Suppose $\mathrm{A}_{\mathrm{sl}}^{\mathrm{j}}>0$ for some $s \in S, l \in L$.

Choose $h \in H$ with $\mathrm{e}_{01}^{\mathrm{h}}>0$ for some $l \in L$. Let h sell $\frac{\Delta}{(1+\overline{\mathrm{r}}(\varepsilon))}$ more of $o l$ and increase his loan by $\left(\frac{\Delta}{(1+\overline{\mathrm{r}}(\varepsilon))}\right) p_{0 l}$. Then he could purchase $\frac{\Delta \cdot \mathrm{p}_{01}}{(1+\overline{\mathrm{r}}(\varepsilon))\left(1+\mathrm{r}_{0}(\varepsilon)\right) \theta_{\mathrm{j}}(\varepsilon)}$ of $j$. Then, by borrowing in $s$ and defraying his loan by asset deliveries he can improve his payoff, a contradiction. The same argument applies if $\mathrm{A}_{\mathrm{sm}}^{\mathrm{j}}>0$ and $\sum_{\mathrm{l} \in \mathrm{L}} \mathrm{p}_{01}(\varepsilon) \nrightarrow \infty$.

Step 13: There exists $K \ni p_{s l}(\varepsilon)<K \forall s \in S^{*}, l \in L$.

Proof: Suppose the contrary and w.l.o.g. suppose that $\mathrm{p}_{\overline{\mathrm{s}} \overline{\mathrm{l}}} \rightarrow \infty$ for some $\overline{\mathrm{s}} \in \mathrm{S}^{*}, \overline{\mathrm{l}} \in \mathrm{L}$.

Since $p_{s l}(\varepsilon)=\frac{\sum_{\mathrm{h} \in \mathrm{H}} \mathrm{b}_{\mathrm{sl}}^{\mathrm{h}}(\varepsilon)}{\sum_{\mathrm{h} \in \mathrm{H}} \mathrm{q}_{\mathrm{sl}}^{\mathrm{h}}(\varepsilon)} \leq \frac{\mathrm{M}^{*}}{\sum_{\mathrm{h} \in \mathrm{H}} \mathrm{q}_{\mathrm{sl}}^{\mathrm{h}}(\varepsilon)}$, it must necessarily be $q_{s l}^{h} \rightarrow 0$ for all $s \in S^{*}, l \in L$ by step 8 . At any $\varepsilon-M E C B D, \bar{r}(\varepsilon), r_{s}(\varepsilon), \rho(\varepsilon)<\delta_{\text {s }}$, by step 3. Hence, at any $\varepsilon-M E C B D$, there are less than $\delta_{s}$-gains from trade. By continuity, there less than $\delta_{\mathrm{s}^{-}}$gains to trade at $\left(e^{h}\right)_{h \in H}$. However, G-from-T hypothesis guarantees that there are more than $\delta_{s}$-gains from trade $\forall s \in S$, a contradiction.

Step 14: $\eta=\lim _{\varepsilon \rightarrow 0} \eta(\varepsilon)$ and $\lim _{\varepsilon \rightarrow 0}(\eta(\varepsilon), \sigma(\varepsilon))=(\eta, \sigma)$.

Proof: From the previous steps, $\eta(\varepsilon)$ is bounded in all components. The same applies for $\sigma(\varepsilon)$. Thus, a convergent susequence can be selected that obtains $(\eta, \sigma)$ in the limit. By continuity of $\Pi^{h}\left(\sigma^{h}\right)$ and $\Pi^{p}\left(\sigma^{b}\right),(\eta, \sigma)$ is a $M E C B D$, and the artificial upper and lower bounds on choices are irrelevant since they are not binding and payoff functions are concave in actions.

\section{Proof of Proposition 1:}

Let $M^{G} \rightarrow \infty$ and consider bounded asset trades. Then by choosing subsequences and further subsequences select a subsequence along which all relative $\sigma$ 's and $\eta$ 's converge. By Propsition III.4.1 and its Corollary III.4.2, the limit of the last subsequence coincides with a GEI, a contradiction. Thus, $\left(\sum_{h \in H} q_{j}^{h}+\sum_{b \in B} q_{j}^{b}\right) \rightarrow \infty$. Thus, by feasibility, $M^{G} / / / \theta_{j} / / \rightarrow \infty$ and $\left[w_{s}(\eta, \sigma) R_{s} m_{s}^{b}\left(1+r_{s}\right)+w(\eta, \sigma) \bar{R} \bar{m}^{b}(1+\bar{r})+\sum_{j \in J} w_{j}(\eta, \sigma) R_{s j}\left(p_{s l} A^{j}\right)\left(b_{j}^{b} / \theta_{j}\right)\right] \rightarrow \infty, \forall s \in S^{*}$, $b \in B$. Finally, by relative boundedness of $\eta^{\prime}$ s (Theorem 1, step 14 ), $M^{G} / / \mid p_{0 l} / / \rightarrow \infty$. Also, $\exists \bar{Z} \ni \nabla \Pi_{s}^{b^{*}}\left(\pi_{s}^{b}\right)>\lambda_{s}^{b^{*}}$ for some $b^{*} \in B$, by Shubik and Tsomocos (1992). Similarly, for some $h^{*} \in H$. Interiority of the maximum on $\pi_{s}^{b}$ and $x_{s}^{h}, \forall s \in S^{*}, b \in B, h \in H$ guarantees bounded aggregate profits and consumptions. 


\section{Proof of Proposition 2:}

From step 4 of Theorem $1, p_{s l}>c, \forall s \in S^{*}, l \in L$. Let $\bar{Q}=1+\max \left\{\left\{\frac{\nabla \Pi_{s}^{b}\left(\pi_{s}^{b}\right)}{\nabla \Pi_{\mathrm{s}^{\prime}}^{b}\left(\pi_{\mathrm{s}^{\prime}}^{b}\right)}: s \in S^{*}, b \in B, \pi_{s}^{b} \in \diamond\right\},\left\{\frac{\nabla \Pi_{s}^{h}\left(x_{s}^{h}\right)}{\nabla \Pi_{\mathrm{s}^{\prime}}^{h}\left(x_{\mathrm{s}^{\prime}}^{h}\right)}: s \in S^{*}, h \in H, x_{s}^{h}<A\right\}\right\} .$,

where $\diamond=\left\{\pi_{\mathrm{s}}^{\mathrm{b}} \in \mathfrak{R}_{+}^{\mathrm{s}+1}: \pi_{\mathrm{s}}^{\mathrm{b}} \leq 1+\max _{0 \leq \mathrm{s} \leq \mathrm{S}} \sum_{\mathrm{b} \in \mathrm{B}} \mathrm{e}_{\mathrm{s}}^{\mathrm{b}}+\max _{0 \leq \mathrm{s} \leq \mathrm{S}} \sum_{\mathrm{h} \in \mathrm{H}} \mathrm{m}_{\mathrm{s}}^{\mathrm{h}}\right\}$.

If some $h$ goes bankrupt then he can reduce his bid on a commodity $l$ by $\varepsilon$ and use this amount to defray his loan. His gain in utility will be $\varepsilon \lambda_{\mathrm{sl}}^{\mathrm{h}}$ whereas his loss will be at most $\frac{\varepsilon \nabla \Pi_{l}^{h}\left(x_{l}^{h}\right)}{p_{l}} \leq \frac{\varepsilon \nabla \Pi_{l}^{h}\left(x_{l}^{h}\right) \bar{Q}}{c}$

Thus, if $\lambda^{*}=\frac{\overline{\mathrm{Q}}}{\mathrm{c}} \max \left\{\nabla \Pi_{l}^{h}\left(x_{l}^{h}, h \in H, l \in L, x_{l}^{h} \in \diamond\right\}\right.$ then as long as $\lambda>\lambda^{*}$ no $h$ will go bankrupt.

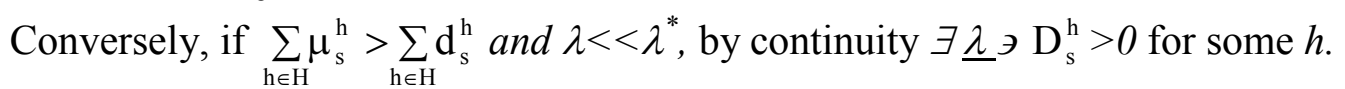

Now since, $\mathrm{q}_{\mathrm{j}}^{\mathrm{b}}=0, \forall j \in J, b \in B$ for $\underline{\lambda} \exists b \in B$ э $\mathrm{D}_{\mathrm{sw}}^{\mathrm{b}}>0$.

\section{Proof of Corollary 1 to Proposition 2:}

Since $u^{b}=u$ and $\lambda_{s}^{b}=\lambda, \forall b \in B$, let $U^{B}=/ B / u^{b}=/ B / u$. Then, $\mathrm{D}_{\mathrm{sw}}^{\mathrm{b}}>0$ implies, $\mathrm{D}_{\mathrm{sw}}^{\mathrm{B}}>0$, for some $s \in S$. Also, because loans exceed deposits $\forall s \in S^{*}, \mathrm{D}_{\mathrm{sw}}^{\mathrm{B}}>0, \forall s \in S^{*}$.

\section{Proof of Corollary 2 to Proposition 2:}

Take $\bar{\lambda}=\bar{\lambda}^{b}=\bar{\lambda}^{h}>\lambda^{*}$ of the proof of proposition 2 and the result follows immediately.

\section{Proof of Theorem 2:}

See Tsomocos (2001). 


\section{Appendix III}

\section{III.1 Money demand, quantity theory of money and the term structure of interest rates}

Quantity theory of money proposition: In a $M E C B$, if $\rho>0$ then the aggregate income at $s \in S$, namely the value of all commodities sales is equal to the total credit provided by commercial banks plus asset payoff liquidity. At $s=0$, aggregate income equals the total central bank money supply plus deposits in the interbank credit market minus expenditures in the asset and equity markets, precautionary reserves and bank profits.

$\sum_{h \in H} \sum_{l \in L} p_{s l} q_{s l}^{h}=\sum_{b \in B} m_{s}^{b}+\sum_{h \in H \cup B} \sum_{j \in J} v_{j}^{h} p_{s} q_{j}^{h} A^{j}+\Delta\left(4^{h}\right) \quad, \forall s \in S$

For $s=0$,

$$
\sum_{h \in H} \sum_{l \in L} p_{0 l} q_{0 l}^{h}=M^{G}+\sum_{b \in B} d^{b}-\sum_{h \in H \cup B} b_{j}^{h}-\sum_{h \in H} \sum_{b \in B} u_{b}^{h}-\Delta\left(4^{h}\right)-\pi_{0}^{b}
$$

Proposition III.1.1: At any $M E C B D, \bar{r}, r_{s}, \geq 0 \quad \forall s \in S^{*}$ and $\bar{r} \geq r_{0} \geq 0$.

Proposition III.1.2: At any $M E C B D, \rho \geq r_{s}, \bar{r} \quad \forall s \in S *$.

Term structure of interest rates proposition: At any $M E C B D, \forall s \in S$,

$$
\left[\sum_{b \in B}\left(m_{0}^{b} r_{0}+m_{s}^{b} r_{s}+\bar{m}^{b} \bar{r}\right)\right]=\sum_{h \in H}\left(m_{0}^{h}+m_{s}^{h}\right)\left(\frac{1}{v_{s}^{h}}\right)+\sum_{b \in B}\left(e_{0}^{b}+e_{s}^{b}\right)\left(\frac{1}{v_{s}^{b}}\right)
$$

(The analogous equation holds with weak inequality for $s=0$.)

Fisher effect proposition: Suppose that for some $h \in H, b_{0 l}^{h}$ and $b_{s l}^{h}>0$, for $l \in L$ and $s \in S$. Suppose, further that h has some money left over the moment that the long loan comes due at $s \in S$. Then, at a MECBD,

$$
(1+\bar{r})=\left(\frac{\frac{\partial u^{h}(x)}{\partial x_{0 l}}}{\frac{\partial u^{h}(x)}{\partial x_{s l}}}\right) \cdot\left(\frac{p_{s l}}{p_{0 l}}\right)
$$

Taking the logarithm of both sides and interpreting loosely, this says that the nominal rate of interest is equal to the real rate of interest plus the (expected) rate of inflation.

\section{III.2 Asset pricing}

Proposition II.2.1: Suppose that $A^{j}=\lambda_{1} A^{1}-\lambda_{2} A^{2}$ and $\lambda_{1}, \lambda_{2} \geq 0$. If asset $j \in J$ is traded at a $M E C B D$ then

$$
\lambda_{1} \theta_{1}-\left(1+r_{0}\right) \lambda_{2} \theta_{2} \leq \theta_{j} \leq \lambda_{1} \theta_{1}-\left(\frac{1}{1+r_{0}}\right) \lambda_{2} \theta_{2} .
$$




\section{III.3 Determinacy and non-neutrality of money and regulatory policy}

Theorem III.3.1: Let $\sum_{h \in H} m_{s}^{h}+\sum_{b \in B} e^{b}>0$ or $\lambda^{b}<\bar{\lambda}^{b}$ and $M^{G}>0$. Then for 'generic (39) economies $E$ the set of MECBD is finite.

Proposition III.3.1: (No money illusion): A proportional increase of all $\left(m_{s}^{h}\right)_{h \in H, s \in S^{*}},\left(e_{s}^{b}\right)_{b \in B, s \in S^{*}}$ and $\left(M^{G}, \mu^{G}, m^{G}, b^{G}\right)$ whereas the regulators' choices of $\kappa$ stay fixed while $\lambda$ 's scaled down proportionally, does not affect the real variables of MECBD.

I define a MECBD to be indecomposable if for any $s \in S^{*}$ and any partition of goods into disjoint sets $L_{1}$ and $L_{2}$ there is some agent $h \in H$ who transacts in at least one commodity from each set in state $s \in S^{*}$.

Proposition III.3.2: Suppose that all $u^{h}, u^{b}$ are differentiable and $m_{s}^{h}, e_{s}^{b}>0$ or $\lambda^{b}<\bar{\lambda}^{b}$ and $\lambda^{h}<\bar{\lambda}^{h}$ for all $h \in H, b \in B$ and $s \in S^{*}$. Suppose at an indecomposable MECBD at every $s \in S^{*}$ all $h \in H$ consume positive amounts of all goods $l \in L$ and that some $h \in H$ carries over money from period 0 to 1 . Then, any change by the government or the regulator (except the one described by Proposition II.3.1) results into a different MECBD in which for some $h \in H$ consumption is different. ${ }^{(40)}$

III.4 Monetary equilibrium with commercial banks and default (MECB) vs. general equilibrium with incomplete markets (GEI) and general equilibrium (GE)

Recall, $\left(p, \pi\left(\chi^{h}, \varphi^{h}\right)_{h \in H}\right)$ is a GEI for the underlying economy

$\mathrm{E}=\left(\left(u^{h}, e^{h}\right)_{h \in H}, A\right)$ iff:

(viii) $\sum_{h \in H} \chi^{h}=\sum_{h \in H} e^{h}$

$$
\sum_{h \in H} \varphi^{h}=0
$$

$$
\left(\chi^{h}, \varphi^{h}\right) \in B^{h}(p, \pi)=\left\{(\chi, \varphi) \in R^{S^{*} \times L}: p\left(\chi_{0}-e_{0}^{h}\right)+\pi \varphi \leq 0, \quad \text { and } \quad \forall s \in S \quad p_{s}\left(\chi_{s}-e_{s}^{h}\right) \leq \sum_{j \in J} \sum_{l \in L} p_{s l} A_{s l}^{j} \varphi_{j}\right\}
$$

$$
(\chi, \varphi) \hat{\imath} B^{h}(p, \pi) \triangleright u^{h}(\chi) £ u^{h}\left(\chi^{h}\right)
$$

Proposition III.4.1: Suppose that $\sum_{h \in H} m_{s}^{h}+\sum_{b \in B} e^{b}=0, "{ }_{s} \hat{\imath} S^{*}, \kappa=0$, and $\lambda=+¥$ Moreover, there exists an asset $A^{j}=(1, \ldots, 1)$. Then MECBD and GEI coincide.

(39) The term 'generic' refers to a set of economies that is open, dense and of full measure.

${ }^{(40)}$ For an extensive discussion see Buiter $(1998,1999)$. 
Corollary III.4.1: If the assumptions of Proposition III.4.1 hold but there does not exist a riskless asset and the long-term credit market is closed, then MECBD and GEI coincide with respect to prices, net asset trades and final consumption.

Corollary III.4.2: Suppose that the assumptions of Proposition III.4.1 hold except that $\sum_{h \in H} m_{s}^{h}+\sum_{b \in B} e^{b}>0$ and that all assets are numeraire

(ie $\left.\exists \bar{l} \in L \ni\left(A_{s \bar{l}}^{j}\right)_{s \in S} \neq 0, \forall j \in J,\left(A_{s l}^{j}\right)_{s \in S}=0, \quad \forall \hat{l} \in L \backslash\{\bar{l}\}\right)$ and that $A^{j}$ 's are linearly independent. Also, let the long-term credit market be closed. Then as $M^{G} \rightarrow \infty$, the MECB attains the GEI prices, net asset trades and final consumption in the limit. ${ }^{(41)}$ Finally, if I impose the restriction that span $[A]=S$ (ie complete markets) the Arrow theorem (1953) holds.

(41) The reason that I require linear independence in numeraire asset matrix is to ensure that net asset trades remain bounded and that the Hart (1975) counterexample does not occur. For more see, Geanakoplos and Polemarchakis (1986). 